SD399. 5 N64

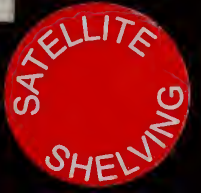




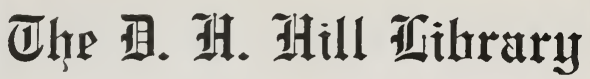

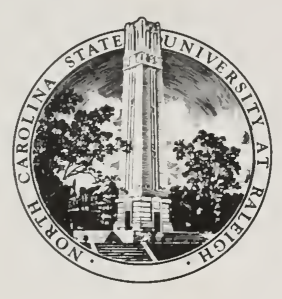

A̛rth Caralina State Alniurraity SD399. 5

N64 
This book is due on the date indicated below and is subject to an overdue fine as posted at the Circulation Desk.

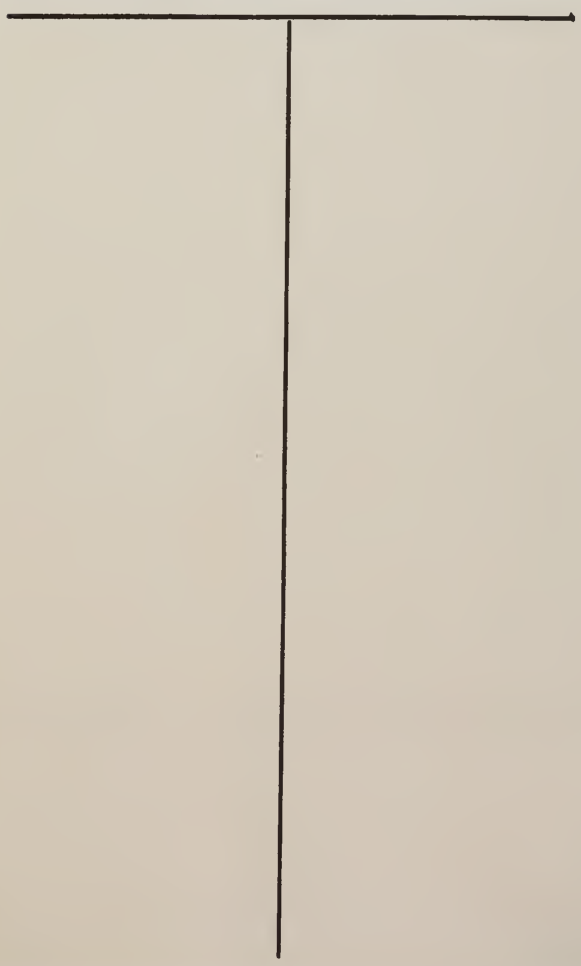




\title{
ANATOMISCHE MERKMALE
}

\author{
DER WICHTIGSTFN DEUTSCHEN
}

\section{WALD- UND GARTENHOLZARTEN.}

BESCHRIEBEN VON

\section{FORSTRATH Dr. NÖRDLINGER, \\ ORD. PROFESSOR AN DER UNIVERSITÄT TÜBINGEN.}

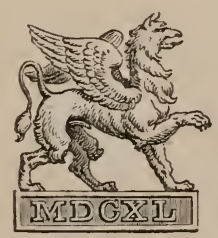

STUTTGART.

VERLAG DER J. G. COTTA'SCHEN BUCHHANDLUNG. 1881.

\section{H. HILL LIBRARY N. C. STATE UNIVERSITY.}


Druck von Gebrüder Kröner in Stuttgart. 


\section{V o r w o r t.}

Als Antwort auf die Anfechtungen welche die Erkennung der Baumart mittelst einer guten Loupe aus dem anatomischen Verhalten des Holzes ursprünglich erfuhr, veröffentlichte ich mit dem II. Bande meiner Querschnitte im Jahr 1856 eine analytische Tabelle zu Bestimmung von 200 Holzarten.

Es fand sich jedoch bald, dass ich für die Fortsetzung meiner Querschnittbände auf die tabellarische Form verzichten musste. Denn schon für 100 Holzarten ist diese unbequem und für 400 , 500 und mehr verbietet sie sich gänzlich.

Lose Tabellen, wie die des Bandes II., beschmutzen sich auch, gehen leicht verloren, und an den Text gebundene zerreissen gern. Beide aber sind weitaus nicht so bequem zu gebrauchen wie in Form fortlaufenden Textes gegebene.

Warum ich mich entschloss die Zahl der in neuerer Zeit erschienenen ähnlichen Schriften um eine zu vermehren, wird unschwer herausfinden, wer sich jener neben der gegenwärtigen bedient.

Das möglichste Wegbleiben aus meiner Arbeit von physikalischen Eigenschaften hat den naheliegenden Grund dass durch letztere nicht selten die Untersuchung auf falsche Fährte geführt wird. Besagt z. B. die Beschreibung des Fichtenholzes dass dieses weich oder leicht, die des Eichenholzes dass solches hart oder schwer sei, so beschränken diese Zusätze die Anwendbarkeit der Karakteristik der beiden Hölzer. Denn es gibt schweres Fichtenholz und leichtes Eichenholz, auf welche jene Bezeichnungen nicht passen und welche doch, wenn die beiden physikalischen Kriterien wegbleiben, alsbald richtig zu erkennen sind.

Was die Ausdrücke Mark, Markfleckchen, Holz- oder Jahresringe, Poren (Röhren oder Gefässe) und Harzporen, gewöhnliches und weitmaschigeres Holzgewebe, endlich Kernholz und Splint bedeuten, brauche ich dem der sich die kleine Mühe gibt einen Weidenzweig mit einem solchen ron Eiche und Föhre zu rer- 
gleichen, nicht zu erläutern. Dagegen scheint es nützlich Beispiele für die verschiedenen Stärkegrade der beiden diagnostischen Hauptelemente: Markstrahlen und Poren, anzuführen.

Markstrahlen nennen wir:

breit, wenn sie die Stärke haben von solchen gemeiner Erle, z. breit,

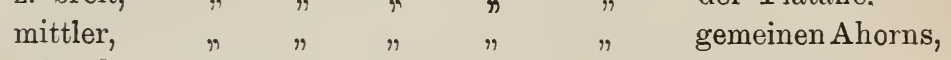
schmal, $" \quad " \quad " \quad " \quad " \quad$ " $"$ der Esche, sehr schmal, " $" \quad " \quad$ " der Birkenwurzel.

Poren dagegen

grob, wenn sie so stark sind als solche gemeiner Eiche, z. grob, " " " " " " " Ulme, mittler, " $" \quad " \quad$ die Aussenporen von Celtis oder Robinie.

z. fein, " " " " " solche gemeinen Ahorns, fein, $" \quad " \quad " \quad " \quad$ von Elsebaum, s. fein, " " " " " " " $"$ Pfaffenhütchen, äusserstfein, $" \quad " \quad " \quad " \quad, \quad$ Stechpalme.

Behufs der Angaben über die auf $1 \square \mathrm{mm}$ kommenden Poren und Porengruppen wurde bei ringporigen Hölzern mit grosser Abweichung der Poren vom Beginne bis zum Schluss des Holzringes dessen Mitte zu Grunde gelegt.

Noch bequemer natürlich macht sich mit dem Bau der Hölzer vertraut, wer $\mathrm{zu}$ den nachstehenden Beschreibungen eine der zahlreichen Sammlungen von Holzquerschnitten zu Hilfe zieht, welche im Buchhandel erschienen und auf dem Umschlage gegenwärtigen Heftes genannt sind.

T ü bỵing e n im Juni 1881. 


\section{Nadelhölzer.}

Auffallend einfaches von feinen Markstrahlen durchzogenes Gewebe aus gleichartigen und, wo die Holzringe nicht fehlen, gegen das Ende dichteren Nadelholzzellen.

Bei einem Theile der Nadelhölzer kommen „Harzporen" vor, welche im Gegensatze zu den Laubholzporen sparsam und einzeln oder zu wenigen in einer Gruppe, selten eigentlich verschmolzen auftreten und gegen die äussere Seite der Hoìringe an Zahl und Grösse eher zu- als abnehmen. Wegen der Gleichartigkeit des Baues hat bei ihnen der Querschnitt eigenthümlichen Atlasglanz.

\section{A. Harzporenlose Nadelhölzer.}

a) Ohne oder fast ohne zerstreute stofferfüllte Holzzellen. - Ohne Kernholz.

Abies pectinata D.C. Tanne. Mark 1 bis $2 \mathrm{~mm}$ dick, eckigrund, braunroth, aus rundlichen, ziemlich feinen Zellen gebildet. Ohne Markfleckchen. - Markstrahlen zahlreich, etwa 8 per mm, schmal, dichter als das umliegende Gewebe, gerade verlaufend. Ohne Harzporen. - Gewebe deutlich schwammig, am Umfange der Ringe dichter, ohne oder fast ohne stofferfüllte Holzzellen. - Holzringe sehr deutlich, regelmässig rund. - Reifholz. Breiter Splint. Farbe röthlichweiss.

b) Meist mit zahlreichen zerstreuten stofferfüllten Holzzellen. Kernhölzer.

1. Kern braungelb.

Juniperus communis $\boldsymbol{L}$. Gemeiner Wachholder. Mark fast 0 , aus wenigen Zellen bestehend, roth. Ohne Markfleckchen. - Markstrahlen zahlreich, etwa 20 per mm, sehr schmal, dichter als das Holzgewebe, gerade bis leichtwellig verlaufend. Ohne Harzporen. - Gewebe sichtbar schwammig, nur am Umfange der Ringe sich festigend. Einzelne erfüllte Zellen. - Holzringe 
deutlich geschieden, grobwellig und gegen den Umfang etwas feinwellig. Röthlichgelbes Kernholz, hauptsächlich durch die, wie auch bei den verwandten Arten, dunkler gefärbten Markstrahlen gebildet.

Thuja occidentalis $L$. Gemeiner Lebensbaum, und orientalis $L$. Mark fast 0, 4eckig, röthlich, aus, wie es scheint, dickwandigen, weniger als äusserst feinen. Zellen gebildet. Ohne Markfleckchen. - Markstrahlen zahlreich, schmal, von dichterem Gewebe, gerade bis leichtwellig verlaufend. Ohne Harzporen. - Gewebe sichtbar schwammig, im Umfang der Ringe etwas dichter. - Holzringe dadurch deutlich geschieden, grob- und leichtfeinwellig. - Kern hellbraun, sich öfters ringförmig verstärkend und dann wieder schwächer werdend. Splint gelblich.

2. Kern roth.

c) Ringe schmal.

Taxus baccata L. Eibe. Mark 0,5 mm dick, 3- bis 5eckig, röthlich, aus ziemlich feinen rundlichen Zellen gebildet. Ohne Markfleckchen. - Markstrahlen zahlreich, schmal, dichter als das Holzgewebe, ziemlich gerade verlaufend. Ohne Harzporen. Gewebe gegen den Umfang der Ringe enger gebaut. - Holzringe dadurch deutlich, grosswellig, rund, und dabei öfters feinwellig. Kern schön braunroth, öfters bläulichroth. Splint weiss oder hellgelb.

Juniperus virginiana $L$. Virginischer Wachholder. Mark fast 0, aus wenigen äusserst feinen Zellen gebildet, dreieckig, älter roth. Ohne Markfleckchen. - Markstrahlen zahlreich, sehr schmal, dichter als das Holzgewebe, etwas wellig verlaufend. Harzporen feh!and oder sehr selten. - Gewebe sichtbar schwammig. Oefters zerstreute Zellen desselben, zumal deutlich im Kern sichtbar, mit Farbstoff erfüllt. :- Holzringe nur am schmalen Umfang fester und dadurch deutlich bezeichnet, grobwellig, sich ausbauchend. Purpurrother gewässerter Kern. Splint schmutzig gelb.

$\beta)$ Ringe breit.

Wellingtonia gigantea Lindl. Wie gemeiner Wachholder aber Markstrahlen zahlreicher und etwas stärker.

\section{B. Harzporenführende Nadelhölzer.}

a) Mit sparsamen Harzporen und hellem Reifholz.

Abies excelsa D.C. Fichte. Mark 1 bis $5 \mathrm{~mm}$ dick, eckigrund, braunroth, aus ziemlich feinen, dünnwandigen, rundlicheckigen Zellen gebildet. Ohne Markfleckchen. - Markstrahlen 
zahlreich, etwa 8 per mm, schmal bis mittler, von dichterem Bau als das übrige Gewebe, gerade verlaufend. - Harzporen etwas abweichend, fein, sehr sparsam, einzeln oder paarweise zerstreut. - Gewebe schwammig, am Ende des Jahresrings massiger. Ohne weitmaschigeres Gewebe. - Holzringe sehr deutlich geschieden, etwas feinwelliger als bei der Tanne, der sie im Uebrigen gleichsteht.

b) Mit zahlreichen Harzporen und rothem Kern.

1. Holz hart.

Larix europaea D.C. Gemeine Lärche. Mark fast null, höchstens $1 \mathrm{~mm}$ dick, eckigrund, roth, aus sehr feinen, ziemlich dickwandigen, eckigrunden Zellen gebildet. Ohne Markfleckclien. - Markstrahlen ziemlich zahlreich, schmal, dichter, ziemlich gerade. - Harzporen an Grösse etwas verschieden, ziemlich sparsam, mit wenig oder ohne Hof von engmaschigerem Gewebe, fein, einzeln, manchmal zu 2 oder 3, etwas kreisig zerstreut. - Gewebe regelmässig, stark schwammig, gegen den Umfang der Ringe sehr eng werdend. - Holzringe eben dadurch auffallend deutlich, breit, etwas wellig kreisrund. - Kern roth, meist etwas purpurroth. Splint gelblich.

Pinus sylvestris $L$. Gemeine Föhre. Mark bald verschwindend klein, bald bis $4 \mathrm{~mm}$ dick, vieleckig zipflig, roth, aus deutlichen, rundlichen, ziemlich dünnwandigen, mittlern und einzelnen noch stärkern Zellen bestehend, die gegen aussen kleiner werden. Ohne Markfleckchen. - Markstrahlen zahlreich, schmal, festern Baues, ziemlich gerade laufend. - Harzporen etwas àbweichend, zahlreich, ziemlich fein bis mittler, einzeln, auch paarweise gleichmässig zerstreut, doch gern eine unregelmässige Linie gegen aussen im Ring bildend. - Holzgewebe deutlich schwammig, regelmässig, in einem breiten Aussenbande der Ringe enger. Etwas engmaschigeres Gewebe um die Poren. - Holzringe sehr deutlich, etwas wellig. - Kern gelblichroth. Splint röthlichweiss.

Pinus laricio var. austriaca Tratt, österreichische, und laricio var. corsicana Loud. korsische Schwarzföhre, von sylvestris nicht wesentlich verschieden.

Pinus montana Mill.. Legföhre. Mark 1 bis $3 \mathrm{~mm}$ dick, vieleckig mit Zipfeln, gelbroth, aus nesterartig verbundenen, ziemlich dünnwandigen, rundlichen, ziemlich feinen, gegen aussen kleiner werdenden Zellen bestehend. Ohne Markfleckchen. - Markstrahlen zahlreich und verschieden, schmal, dichter als das Holzgewebe, ziemlich gerade. - Harzporen abweichend, für ein Nadelholz ziemlich zahlreich, ziemlich fein, einzeln, paarweise, manchmal 3 , bis 4, gleichmässig zerstreut. - Gewebe ziemlich regel- 
mässig, deutlich schwammig, um die Poren als engmaschiger Hof. - Holzringe eng und wellig, durch den breiten, festeren, harzreichen? Aussentheil der Holzringe augenfällig bezeichnet, oft excentrisch. - Kern gelbroth, häufig nicht gleichförmig vertheilt.

\section{Holz weich.}

Pinus cembra L. Arve. Mark 1 bis $6 \mathrm{~mm}$ dick, rundeckig, mit ungleich grossen, runden, dünnwandigen, ziemlich feinen Zellen. Rossmässler fand bei ihr Markfleckchen. - Markstrahlen zahlreich, schmal, dichter als das Holzgewebe, ziemlich gerade. Harzporen wenig verschieden, ziemlich zahlreich, mittler bis ziemlich fein, einzeln, zu 2, selten zu 3, hauptsächlich gegen den Umfang der Holzringe stehend. - Gewebe deutlich schwammig, ziemlich unregelmässig, gegen den Umfang der Ringe allmählig dichter werdend. - Holzringe desshalb deutlich geschieden; regelmässig kreisrund. - Kern gelbroth. Splint gleichmässig.

Pinus strobus $L$. Weymouthsföhre. Mark $1 \mathrm{~mm}$ dick, eckigrund, roth, aus feinen dünnwandigen Zellen gebildet. Ohne Markfleckchen. - Markstrahlen zahlreich, schmal, dichter als das übrige Gewebe, ziemlich gerade verlaufend. - Harzporen an Grösse etwas abweichend, ziemlich zahlreich, mittler, einzeln, zu 2, manchmal 3, im äussern Theil der Ringe zerstreut, bei engern Ringen eine leichte Linie bildend. - Gewebe ziemlich unregelmässig; etwas engmaschiger Hof um die Poren. - Holzringe gegen den Umfang allmählig dichter werdend, deutlich, fast ganz kreisrund. - Kern rothgelb, öfters gewässert, im obern Stamm bläulichroth.

\section{Laubhölzer.}

Gewebe engmaschiger als bei den Nadelhölzern und mit augenfälligen zahlreichen zerstreuten oder in verschiedener Weise gruppirten Poren.

Diese Laubholzporen, sofern sie nicht nahezu von gleicher Grösse sind, gegen den Umfang der Holzringe fast immer unscheinbarer und kleiner werdend.

\section{A. Holzringe nicht oder undentlich geschieden.}

Vitis vinifera $L$. Weinrebe. Mark 2 bis $4 \mathrm{~mm}$ dick, rund, braun, aus mittlern bis gröblichen, mit einzelnen gröblichen durchmischten, dünnhäutigen eckigrunden Zellen gebildet. Ohne iMark- 
fleckchen. - Markstrahlen sehr zahlreich, etwa 3 per mm, ziemlich breit bis breit, fester, ziemlich gerade verlaufend. - Poren von sehr verschiedener Grösse, sehr zahlreich, etwa 6 per $\square \mathrm{mm}$, dem Holze siebartiges Ansehen verleihend, grob, 1, 2, 3, bis, in den schwanzförmigen Verlängerungen der Gruppen, 12, schwanzförmig, gleichmässig. - Gewebe ziemlich fein, mit kaum nennenswerthen radialen Linien weitmaschigeren Gewebes. - Holzringe mehr oder weniger undeutlich, etwas wellig. - Holz röthlich weiss.

\section{B. Holzringe dentlich geschieden, jedoch ohne eigentliche Linie oder Binde besonders grober oder zahlreicher Poren am Anfange der Holzringe.}

a) Das weitmaschigere Gewebe, in Form flammenartig verzweigte'r Stellen, die freien Räume zwischen den Poren ausfüllend (Ahornarten).

«) Dichte Hölzer.

Acer campestre L. Massholder. Mark klein, $1 \mathrm{~mm}$ dick, etwas eckigrund, röthlich, aus dünnwandigen, rundlicheckigen, feinen Zellen gebildet, mit schmalem Ring dunkelgefärbten, feinkörnigen Gewebes. - Grosse einzelne Markfleckchen. - Markstrahlen zahlreich, etwa 8 per mm, schmal, dichter als die Umgebung, sich vielfach auskeilend, von geradem Verlaufe. - Poren gleichförmig, mittler zahlreich, etwa 40 per $\square \mathrm{mm}$, ziemlich fein bis fein, einzeln, paarweise, manchmal zu 3, gleichmässig zerstreut. — Gewebe ziemlich undurchsichtig. Weitmaschigeres Gewebe deutlich durchsichtig in Form flammenartig verzweigter, schwammiger Stellen in den freien Räumen zwischen den Poren, da und dort etwas kreisig. - Holzringe durch eine dunkle Sommerlinie deutlich, leichtwinklig. - Holz röthlich.

Acer negundo L. Eschenblättriger Ahorn. Mark wie bei dasycarpum, aber grünlichgelb, später weissgelb. Ohne Markfleckchen. - Markstrahlen sehr zahlreich, mittler, fester als die Umgebung; die stärkern gerade, die schwachen geschlängelt. Poren etwas abweichend, sehr zahlreich, fein, 1 bis 4, manchmal 5, gleichmässig zerstreut. - Gewebe etwas schwammig, daher das auf freien Stellen stehende weitmaschigere Gewebe wenig auffallend. Holzringe wie bei Massholder kaum leichtwellig. - Holz hellgelb.

Acer platanoides $\boldsymbol{L}$. Spitzahorn. Mark 1 bis einige mm dick, eckigrund, röthlich- oder gelblichweiss, aus dünnwandigen gleichförmigen, ziemlich feinen Zellen gebildet. Ohne Markfleckchen. - Markstrahlen sehr zahlreich, etwa 7 per mm, mittler, fester 
als die Umgebung, geradelaufend, nur die feinsten etwas ausweichend. - Poren ziemlich gleichförmig, mittler zahlreich, 20 bis 30 per $\square \mathrm{mm}$, ziemlich fein, zu 1, 2, 3, manchmal 4 oder 5, gleichmässig zerstreut. - Gewebe ziemlich schwammig, doch weitmaschigeres leicht erkennbar, wie bei den anderen Ahornen. - Holzringe deutlich feinwellig. - Splintbaum. - Holz weiss oder gelblich.

Acer pseudoplatanus $L$. Gemeiner A horn. Mark einige mm dick, rund, röthlich-oder gelblichweiss, aus dickwandigen zweierlei bräunlichen Zellen bestehend. Ohne Markfleckchen. - Markstrahlen mittler. Poren, Gewebe etc. dem vorigen gleich, nur Holzringe schön gerundet. - Holz weiss, leicht ins Röthliche stechend.

$\beta$ ) Weiches Holz.

Acer dasycarpum L. Silberahorn. Mark 1 bis $3 \mathrm{~mm}$ dick, eckigrund, röthlich, aus dünnwandigen, rundlicheckigen, mittlern bis gröblichen Zellen gebildet. Ohne Markfleckchen. - Markstrahlen zahlreich, etva 7 per mm, mittler, dichter als die Umgebung, sich öfters auskeilend. - Poren gleichförmig, ziemlich fein, zahlreich, etwa 20 bis 30 per $\square \mathrm{mm}$, zu 1, 2, manchmal 3, gleichmässig zerstreut. - Gewebe deutlich schwammig, mehr als bei den anderen Ahornen. Weitmaschigeres Gewebe wie bei Massholder, da und dort vom gewöhnlichen Gewebe wenig zu unterscheiden. - Holzringe wie bei Massholder, schön gerundet. - Kernfarbe braun, Splint röthlich weiss.

b) Mit unscheinbarem, meist nur an sehr dünnem Schnitte sichtbaren, besondersinstrahligen Linien, doch öfters auch kreisig oder hofähnlich anzusehenden weitmaschigeren Gewe be.

1. Poren sehr fein oder fein.

Buxus sempervirens $\boldsymbol{L}$. Buchs. Mark 0,3 bis $1 \mathrm{~mm}$ dick, länglich viereckig, grünlich, mit dickwandigen, eckigrunden, äusserst feinen Zellen. Ohne Markfleckchen. - Markstrahlen ziemlich zahlreich, etwa 12 per mm, sehr schmal, von gröberem (?) Gewebe, gerade verlaufend, in der Stärke häufig etwas anschwellend und sich auskeilend. - Poren wenig abweichend, nicht sehr zahlreich, weil sehr fein, doch etwa 100 per $\square$ mm, einzeln, gleichmässig zerstreut. - Gewebe da und dort noch sichtbar, mit unbedeutendem Zellraum. Weitmaschigeres Gewebe nesterweise in der Umgebung der Poren. - Holzringe deutlich, hauptsächlich durch das porenarme Sommerholz, da und dort auch durch etwas stärkere Anfangsporen in die Augen fallend, leichtwellig. Holz gelb. 
Philadelphus coronarius $L$. Gemeiner Pfeifenstrauch. Mark $3 \mathrm{~mm}$ dick, schön ruud, weiss, mit groben, dünnwandigen, rundeckigen Zellen. Ohne Markfleckchen. - Markstrahlen sehr zahlreich, etwa 15 per $\mathrm{mm}$, mittler, dazwischen, fast ohne Uebergang, sehr feine Strahlen. Die starken fast gerade verlaufend. - Poren ziemlich gleichförmig, ziemlich zahlreich, etwa 50 Poren und Porengruppen per $\square \mathrm{mm}$, einzeln und paarweise, doch auch 4, 5 in einer Gruppe, fein, gleichmässig zerstreut. - Gewebe fein mit meist strahligem (kleine Markstrahlen?), da und dort nesterweisen Schichtgewebe. - Holzringe fürs blosse Auge deutlicher als für die Loupe, da der stärkere Porenkreis häufig fehlt, im Uebrigen ziemlich schön rund. Grünlichgelbliches Holz.

Ribes nigrum $L$. S chwarze Johannisbeere. Mark 1 bis $3 \mathrm{~mm}$ dick, fünfeckigrund, braun, aus nesterartig verbundenen, theilweise farberfüllten, rundeckigen, dünnwandigen Zellen gebildet. Ohne Markfleckchen. - Markstrahlen theils mittler bis breit, sparsam, etwa 3 per mm, von etwas lockerem Gewebe, theils sehr fein und zahlreich, beide gerade verlaufend. - Poren wenig verschieden, sehr zahlreich, vielleicht 400 per $\square \mathrm{mm}$, eiförmig, sehr fein, zu 1, 2, selten 3 in einer Gruppe, gleichmässig zerstreut, dabei aber etwas ringförmig, wurmähnlich. - Gewebe fein, weitmaschigeres meist strahlenförmig. - Holzringe deutlich durch dichteres Sommerholz und die Reihenstellung der Frühlingsporen, ziemlich schön rund, doch mit, den Markstrahlen folgenden, Zipfeln. - Holz weiss.

2. Poren gröblich.

Juglans regia $\boldsymbol{L}$. Gemeiner Nussbaum. Mark ziemlich stark, 2 bis $5 \mathrm{~mm}$ dick, eckigrund, braun, aus dünnwandigen, gröblichen Zellen gebildet. Beim gespaltenen Holz in Folge des Schwindens eine Reihe hohler platter Fächer bildend, die sich bei allen eigentlichen Juglans-Arten finden. Ohne Markfleckchen. Markstrahlen zahlreich, etwa 8 per $\mathrm{mm}$, mittler breit, von kaum dichterem Bau, den Poren ausweichend. - Poren abweichend, mittler zahlreich, etwa 6 per $\square \mathrm{mm}$, gröblich, einzeln, paarweise auch manchmal zu 3 oder 4 , gleichmässig zerstreut. - Gewebe grobschwammig mitkurzen, feinen, welligkreisigen dunkleren Linien weitmaschigeren Gewebes. - Holzringe durch schmale dunkle Sommerlinie und häufig auch grossporige unbedeutende Frühlingslinie oder -zone und hier schwammigeres Gewebe deutlich, gleichförmig, etwas wellig. - Kern braun bis schwarzbraun, Splint schmutzigweis.

Juglans nigra $\boldsymbol{L}$. Schwarznuss, wie die vorige. - Holzringe etwas wellenförmiger. 
c) Ohne weitmaschigeres Gewebe.

1. Mit mässig viel grossen Markstrahlen und zwischen diesen ausgebauchten Jahresringen.

Alnus glutinosa Willd. G e meine Erle. Mark klein, 1 bis $2 \mathrm{~mm}$ dick, dreieckig, roth, mit sichtbaren, sehr feinen Zellen. - Zahlreiche, im Sommer- und Herbstholz stehende, oft leichte Kreise bildende Markfleckchen. - Markstrahlen sehr zahlreich, etwa 12 per mm, ziemlich breit bis breit, zusammengesetzt, feiner als das umliegende Gewebe, gerade verlaufend; nur die feinen Markstrahlen den Porengruppen ausweichend. - Poren unbedeutend abweichend, ziemlich zahlreich, etwa 40 per $\square \mathrm{mm}$, fein, 1 bis 5 , manchmal 6, gleichförmig zerstreut, manchmal etwas verzweigt oder kreisig. - Gewebe deutlich grobschwammig, ohne weitmaschigeres Gewebe. - Holzringe schön deutlich durch porenloses dichtes Sommerholz und aus kleineren zahlreichen Poren gebildetes Frühlingsholz; durch gewölbte Vorsprünge zwischen den starken Markstrahlen wellig. - Holz röthlich, meist stark gebändert, weich.

Alnus viridis D.C. Bergdrossel. Wie die vorhergehende, aber Markflecken weniger zahlreich und kleiner, auch Poren bis zu 10 in einer Gruppe.

Fagus sylvatica $\boldsymbol{L}$. Gemeine Buche. Mark sehr klein, $1 \mathrm{~mm}$ dick, 3 bis 5eckig, röthlich, aus dickwandigen, äusserst feinen Zellen gebildet. Ohne Markfleckchen. - Markstrahlen zahlreich, etwa 8 per mm, ziemlich breit bis breit, von feinerem Gefüge, im Verlauf manchmal etwas absetzend, häufig etwas ausweichend. Poren wenig abweichend, sehr zahlreich, etwa 70 Poren und Porengruppen per $\square \mathrm{mm}$, einzeln, 2, 3, auch 4 oder 5 in einer Gruppe, fein, gleichfö:mig zerstreut. - Gewebe dicht, kaum da und dort sichtbar, ohne weitmaschigeres Gewebe, doch mit einzelnen gröberen Zellen besäet. - Holzringe schön deutlich durch porenarmes Herbstholz neben dem porenreichen Frühlingsholze, zwischen den Markstrahlen schön auswärts gewölbt. - Holz röthlichweiss, dicht.

2. Mit sehr vielen starken Markstrahlen und etwas eingebauchten Holzringen.

Platanus vulgaris Spach. Gemeine Platane. Mark klein, bis einige mm dick, eckigrund, bräunlich, aus feinen, regelmässig in die Markstrahlen mündenden, in der Mitte dünnwandigen, leichteckigen, ganz aussen kleiner werdenden Zellen gebildet. Ohne Markfleckchen. - Die Markstrahlen sehr zahlreich, etwa 3 per mm, ziemlich breit, von dichterem Gefüge, gerade verlaufend. - Poren wenig abweichend, sehr zahlreich, etwa 20 Poren und Porengruppen 
per $\square \mathrm{mm}, 1$ bis 5, manchmal 6, ziemlich fein, gleichmässig zerstreut. - Gewebe deutlich schwammig, mit einzelnen gröberen Zellen durchschossen. - Holzringe zwar deutlich, aber nur mit einer Linie von Sommerholz, ziemlich schön rund, etwas eingebaucht. Kern braun, Splint röthlichweiss.

3. Ohne grosse Markstrahlen. Gewöhnliche gerundete Holzringe.

c) Poren sparsam, in radialen Linien und Nestern, im Ganzen gleichmässig vertheilt. Linden:

Tilia grandifolia Ehrh., grossblättrige Linde, und Tilia parvifolia Ehrh., kleinblättrige Linde. Mark klein, $2 \mathrm{~mm}$ dick, 3- bis 5eckig rund, weiss, aus etwas gemischten, ziemlich dünnwandigen, ziemlich feinen, am Umfang feinkörnigern Zellen gebildet. Ohne Markfleckchen. - Markstrahlen zahlreich, etwa 7 per mm, schmal bis mittler, dichter, ziemlich gerade verlaufend, doch den groben Porengruppen ausweichend. - Poren an Grösse ziemlich schwankend, ziemlich sparsam, etwa 40 Poren und Porengruppen per $\square \mathrm{mm}, 1$ bis 3, manchmal 4 oder 5 , vielfach in Strahlen, auch sich stark drückend und Nester bildend, fein, gleichmässig zerstreut. - Gewebe schwammig und unregelmässig gebaut, stellenweise weiter- oder engermaschig. - Holzringe deutlich durch das Sommerholz, wenig durch Frühlingsporen ausgezeichnet, kreisig, aber zwischen den Markstrahlen häufig etwas unregelmässig verlaufend. - Holz weiss.

$\beta)$ Poren reichlich, gleichmässig, öfters etwas wurmförmig vertheilt.

Aesculus hippocastanum $L$. Rosskastanie. Mark 2 bis $4 \mathrm{~mm}$ dick, viereckigrund, weiss, aus rundeckigen, dünnwandigen feinen Zellen gebildet. Ohne Markfleckchen. - Markstrahlen sehr zahlreich, etwa 15 per $\mathrm{mm}$, sehr schmal, fester als das umgebende Gewebe, leicht geschlängelt. - Poren gleichmässig, ziemlich zahlreich, etwa 40 Poren und Porengruppen per $\square \mathrm{mm}$, sehr fein, zu 1 bis 6 , auch 7, gleichmässig zerstreut, etwas verzweigt. Gewebe (noch sichtbar) schwammig. Ohne weitmaschigeres Gewebe. - Holzringe deutlich, manchmal etwas verwaschen durch schwammigeres Gefüge des porenlosen Sommerholzes; da und dort ein porenreicherer Frühlingsring; sehr schön gerundet. - Holz rein weiss.

Cornus mascula L. Kornelkirsche. Mark klein, $1 \mathrm{~mm}$ dick, eckigrund, bräunlich, aus ziemlich feinen bis mittlern dünnwandigen eckigen Zellen gebildet. Ohne Markfleckchen. - Markstrahlen sehr zahlreich, etwa 12 per mm, mittler breit, lockerer als die Umgebung, sich vielfach auskeilend, nahezu gerade. - Poren 
von abweichender Stärke, besonders gegen den Umfang der Holzringe, ziemlich zahlreich, etwa 40 per $\square \mathrm{mm}$, ziemlich fein, einzeln manchmal paarweise, mit den Markstrahlen paralleler Scheidewand, gleichmässig zerstreut. - Gewebe kaum sichtbar, ohne weitmaschigere Partieen. - Holzringe ziemlich deutlich durch meist schmalen Saum porenärmeren Sommerholzes und häufig eine Frühlingsporenlinie, etwas bauchig gerundet. - Kern dunkelbraunroth, Splint röthlich- oder gelblichweiss.

Cornus sanguinea $L$. Hartriegel. Mark klein, 1 bis $2 \mathrm{~mm}$ dick, eckigrund, weiss, mit deutlichen, dünnwandigen, eckigen, ziemlich feinen Zellen. Ohne Markfleckchen. - Markstrahlen sehr zahlreich, etwa 4 per mm, mittler breit, kaum festern Gefüges, sich häufig auskeilend, gerade rerlaufend. - Poren an Grösse ziemlich abweichend, zahlreich, etwa 50 Poren und Porengruppen per $\square \mathrm{mm}$, einzeln, manchmal parrweise, dabei die Scheidewand in der Regel in der Richtung der Markstrahlen, auch zu 3 oder 4, schwach ziemlich fein, gleichmässig zerstreut, etwas verzweigt. Gewebe kaum sichtbar, ohne weitmaschigere Partieen. - Holzringe deutlich, durch porenarmes festes Sommerholz, und, wenn auch das Frühlingsholz ebenfalls porenarm, so doch durch eine deutliche Porenlinie bezeichnet. Oefters Doppelringe und die Holzringe gegen aussen wellig gerundet. - Kern fleischroth, Splint grünlichgelb.

Crataegus oxyacantha $\boldsymbol{L}$. Gemeiner Weissdorn. Mark klein, $1 \mathrm{~mm}$ dick, rund oder eckigrund, weiss, aus rundlicheckigen, dickwandigen, sehr feinen Zellen zusammengesetzt. - Markfleckchen bäufig und auffallend. - Markstrahlen sehr zahlreich, etwa 10 per mm, schmal, von festerem Gefüge, leicht geschlängelt, - Poren wenig abweichend, sehr zahlreich, etwa 100 Poren und Porengruppen per $\square \mathrm{mm}$, einzeln, manchmal paarweise, selten 3 , gleichmässig zerstreut. - Gewebe kaum sichtbar porös. Ohne weitmaschigeres Gewebe. - Holzringe deutlich durch etwas festeres Sommerholz oder wenigstens eine deutliche dunkle Umfangslinie, auch porenreicheres Frühlingsholz, etwas wellig gerundet. - Holz matt fleischroth.

Evonymus europaeus $\boldsymbol{L}$. Pfaffenhütchen. Mark $2 \mathrm{~mm}$ dick, viereckigrund, weiss, aus dickwandigen, sehr feinen Zellen zusammengesetzt, am Umfang grün. Ohne Markfleckchen. Markstrahlen sehr zahlreich, etwa 12 per mm, sehr fein, dichter, etwas geschlängelt. - Poren wenig abweichend, ziemlich zahlreich, etwa 150 per $\square \mathrm{mm}$, einzeln, manchmal paarweise, auch zu 3, sehr fein, gleichmässig zerstreut. - Gewebe schwammig und unregelmässig, die Poren etwas nesterweise darin stehend. Ohne weitmaschigeres Gewebe. - Holzringe deutlich, durch porenarmes 
Herbstholz und da und dort ein Band oder eine Linie porenreichern Frühlingsholzes schön, aber etwas wellig rund und den Markstrahlen nach gegen aussen leicht zipflig. - Kern braun, Splint schön gelblichweiss.

Liriodendron tulipifera $L$. Tulpenbaum. Mark 2 bis $4 \mathrm{~mm}$ dick, rund oder länglich, weiss, aus mittlern bis gröblichen, rundlicheckigen, dünnwandigen, nur im dunkeln Umfange kleinern Zellen gebildet. Ohne Markfleckchen. - Markstrahlen sehr zahlreich, etwa 8 per mm, mittlerbreit, dichter als das Holzgewebe, geschlängelt.

Poren ziemlich abweichend, zahlreich, etwa 50 Poren und Porengruppen per $\square \mathrm{mm}$, ziemlich fein, 1 bis 6 , selten 7 oder 8 , oft stark gedrückt, Nester, weniger Linien bildend als bei der verwandten Linde, gleichförmig zerstreut. - Gewebe schwammig, ohne weitmaschigere Zellen. - Holzringe bloss durch die deutliche dunkle Sommerlinie, selten durch Frühlingsporenreichthum geschieden, etwas wellig. - Kern braun. Splint gelblichweiss.

Pirus aria L. Mehlbaum. Anatomisch wie Pyrus malus, aber mit häufigen Markfleckchen gegen die Mitte. - Poren meist sparsamer im äussern Theil der Holzringe, somit letztere deutlicher als bei malus, etwa 90 Poren und Porengruppen per $\square \mathrm{mm}$. - Kern braunroth, gewässert. Splint röthlichweiss oder weiss.

Pirus communis L. Birnbaum. Mark klein, 1 bis $2 \mathrm{~mm}$ dick, rund, weiss, aus ziemlich dickwandigen, rundlichen feinen Zellen zusammengesetzt. Ohne Markfleckchen. - Markstrahlen sehr zahlreich, etwa 13 per mm, schmal bis mittler, kaum dichter, nur schwach geschlängelt. - Poren wenig verschieden, sehr zahlreich, zu etwa 60 Poren und Porengruppen per $\square \mathrm{mm}$, aber wechselnd; einzeln, zu 2 oder 3, manchmal 4 und 5 , fein, gleichmässig zerstreut, etwas wurmförmig. - Gewebe noch sichtbar mit einzelnen gröbern Zellen und Zellenlinien. - Holzringe deutlich durch dunklere Sommerlinie und meist Frühlingsporenlinie, etwas welligrund. Holzfarbe rothbraun oder braunroth.

Pirus malus L. Apfel ba um. Mark klein, 1 bis $3 \mathrm{~mm}$ dick, rundeckig, weiss, aus rundlichen, feinen, im Umfange kleineren Zellen zusammengesetzt. Ohne Markfleckchen. - Markstrahlen sehr zahlreich, etwa 9 per mm, schmal bis mittler, kaum dichter, nur wenig ausweichend. - Poren wenig verschieden, sehr zahlreich, etwa zu 60, aber wechselnd, fein, 1, 2, 3, manchmal 4 oder 5, gleichmässig zerstreut. - Gewebe nicht mehr sichtbar, doch mit einzelnen weitmaschigeren Zellen und Zellenlinien. - Holzringe fast überall nur durch eine schmale, dunkle Sommerlinie geschieden, daher nicht sehr deutlich, welligrund. - Kern hellbraunroth. Splint röthlichweiss. 
Pirus torminalis L. Elsebeer. Mark beiläufig $2 \mathrm{~mm}$ dick, 5- bis 6eckigrund, röthlichgelb, aus feinen, dünnwandigen, rundlicheckigen, etwas nesterartigen Zellen. - Holz röthlichweiss. Im Uebrigen wie malus.

Sorbus aucuparia L. Vogelbeer. Mark klein, $1 \mathrm{~mm}$ dick, eckigrund, weiss, mit ziemlich dünnwandigen, rundeckigen, ziemlich feinen Zellen. - Markfleckchen häufig gegen die Mitte, und gegen aussen durch Markstrahlen geschwänzt. - Markstrahlen sehr zahlreich, etwa 10 per mm, schmal, dichter, leicht geschlängelt. - Poren wenig abweichend, sehr zahlreich, etwa 100 Poren und Porengruppen per $\square \mathrm{mm}$, einzeln, zu 2,3, manchmal zu 4 oder 5, fein, gleichmässig zerstreut. - Gewebe locker mit einzelnen weiteren Holzzellen. - Holzringe schön deutlich durch eine dunkle Linie oder einen breiteren Streifen porenärmeren Sommerholzes, auch häufig eine Linie oder eine Zone porenreicheren Frühlingsholzes, hübsch gerundet. - Kern rothbraun. Splint schmutzig röthlichweiss.

Sorbus domestica $L$. Sperberba um. Mark 1 bis $2 \mathrm{~mm}$ dick, eckigrund, röthlich, mit ungleichen, zum Theil gefärbten vollen, eckigrunden, ziemlich dickwandigen, sehr feinen bis feinen Zellen. - Markfleckchen ziemlich zahlreich, dunkel. - Markstrahlen äusserst zahlreich, etwa 12 per mm, schmal, von dichterem Gewebe, etwas geschlängelt. - Poren an Grösse wenig abweichend, sehr zahlreich, etwa 100 Poren und Porengruppen per $\square \mathrm{mm}$, einzeln, zu 2, 3, manchmal 4 oder 5, gleichmässig zerstreut. Gewebe etwas sichtbar schwammig, mit einzelnen weiteren Holzzellen. - Holzringe nicht sehr auffallend, doch deutlich durch eine dunkle Sommerholzlinie bezeichnet, etwas welligrund. Kern dunkel rothbraun, häufig gewässert. Splint hellbraunroth.

Staphylea pinnata L. Pimpernuss. Mark $3 \mathrm{~mm}$ dick, eckigrund, weiss, aus sichtbaren groben Zellen gebildet. Ohne Markfleckchen. - Markstrahlen zahlreich, etwa 12 per mm, ziemlich breit, dichter als das Gewebe, von geradem Verlauf, aber in der Breite schwankend. - Poren ziemlich gleichmässig, sehr zahlreich, etwa 50 Poren und Porengruppen per $\square \mathrm{mm}$, fein, zu 1, 2, selten 3, gleichmässig zerstreut. - Gewebe schwammig, besonders im Sommerholze, das sehr häufig hellere Ringe bildet, neben strahligen Linien und zerstreuten weitmaschigern Zellen. - Holzringe deutlich, doch da und dort am Schlusse sich verdoppelnd; etwas welligrund. Frühlingsholz nur ausnahmsweise in deutlicher Porenlinie angesetzt. - Holz gelblich- oder grünlichweiss.

Viburnum lantana $L$. Schlingstra uch. Mark 2 bis $5 \mathrm{~mm}$ 
dick, 4- bis 6eckigrund, weiss oder röthlich, aus dünnwandigen, rundeckigen, etwas nesterförmig gruppirten gröblichen Zellen gebildet. Ohne Markfleckchen. - Markstrahlen zahlreich, etwa 14 per mm, schmal, fester als die Umgebung, wenig ausweichend. - Poren ziemlich zahlreich, etwa 60 Poren und Porengruppen per $\square \mathrm{mm}$, merklich abweichend, besonders gegen den Umfang der Holzringe fein, eiförmig, einzeln, auch zu zwei, mit radialer Scheidewand, manchmal 3 oder 4, gleichmässig vertheilt, etwas wurmförmig. - Gewebe noch sichtbar schwammig, mit etwas weitmaschigern Strahlen. - Holzringe ziemlich deutlich durch porenärmeres und kleinerporiges Herbstholz und eine einfache, gröberporige Frühlingslinie, etwas geschwungen rund. - Kern gelbbraun. Splint weiss oder gelblichweiss.

Viburnum opulus $\boldsymbol{L}$. Gemeiner Schneeball, Wasserholder. Mark 1 bis $5 \mathrm{~mm}$ dick, rundlichviereckig, weiss, aus etwas nesterförmig gruppirten, dünnwandigen, rundlicheckigen Zellen gebildet. Ohne Markfleckchen. - Markstrahlen sehr zahlreich, etwa 15 per mm, schmal, dichter als das umliegende Gewebe, ziemlich geschlängelt, den Poren ausweichend. - Poren wenig abweichend, zahlreich, etwa 60 Poren und Porengruppen per $\square \mathrm{mm}$, ziemlich fein bis fein, einzeln, zu 2, 3, manchmal 4 oder 5 , gleichmässig, etwas wurmförmig zerstreut. - Gewebe sichtbar schwammig, mit radialen weitmaschigeren Linien. _ Holzringe ziemlich deutlich durch etwas porenärmeres Sommerholz, eine feine dunkle Linie und eine Linie gröberer Frühlingsporen, etwas geschlängelt kreisig. - Kern gelbbraun. Splint weiss oder röthlich.

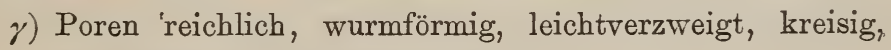
oder etwas dendritisch vertheilt.

Alnus incana L. Grauerle. Nur selten mit einzelnen und nur ziemlich breiten Markstrahlen, auch dazwischen wenig bauchigen, zuweilen eher eingebauchten Holzringen. Sonst wie Alnus glutinosa, gemeine Erle S. 12.

Salix alba $\boldsymbol{L}$. Weissweide. Mark in Grösse wechselnd, doch meist nicht unbedeutend, 2 bis $5 \mathrm{~mm}$ dick, eckigrund, weiss, später gelblich oder bräunlich, aus dünnwandigen, eckigen, gröblichen Zellen gebildet. Ziemlich häufig Markfleckchen. - Markstrahlen sehr zahlreich, etwa 8 per mm, sehr fein, geschlängelt, von dichterem Gewebe. - Poren unbedeutend abweichend, aber gegen das Ende des Holzrings kleiner, sehr zahlreich, etwa 50 Poren und Porengruppen per $\square \mathrm{mm}$, einzeln, manchmal paarweise, auch zu 3, im Sommerholz selbst 5 in einer Gruppe, ziemlich fein, manchmal schwach mittler, gleichmässig zerstreut, etwas wurmförmig. - Schwammiges Gewebe in Form zerstreuter Zellen und 
strahliger Linien. - Holzringe deutlich durch kleinerporiges Herbstholz und da und dort eine auch oft fehlende. Linie oder ein Band porenreicheren Frühlingsholzes, etwas eckiggerundet.Kern schmutzig gelbroth. Splint weiss.

Salix caprea L. Salweid e. Sparsame Markfleckchen. Etwa 12 Markstrahlen per mm. - Poren reichlich, bis 50 Poren und Porengruppen per $\square \mathrm{mm}$ und bis 7 Poren in einer Gruppe. - Holzringe im stärkern Stamme zipflig. - Kern gewässert braungelb. Splint gelblich oder röthlichweiss. Sonst wie alba.

Salix daphnoides Pers. Lorbeerweide. - Ohne Markfleckchen. - Markstrahlen 12 per mm, etwa 80 Poren und Porengruppen per $\square \mathrm{mm}$. - Holz gelblichweiss. Sonst wie alba.

Salix fragilis L. Knackweide. Ohne Markfleckchen. Markstrahlen etwa 12 per mm. - Poren (immer?) etwa 40 per $\square \mathrm{mm}$. - Holzringe in stärkern Stämmen zipflig. - Kern gelbroth, gewässert. Splint hellgelb.

Salix triandra L. (amygdalina L.) Mandelweide. - Mit Markfleckchen. - Narkstrahlen etwa 14 per mm. - Poren etwa 60 per $\square \mathrm{mm}$, schwach ziemlich fein. - Holzringe welligrund. Kern hellbräunlichroth, allmählich in den weissen Splint übergehend.

$\delta)$ Poren reichlich, dendritisch vertheilt.

Betula alba $L$. Gemeine Birke. Mark sehr klein, etwa $1 / 2 \mathrm{~mm}$ dick, länglich oder dreieckig, bräunlich, aus äusserst kleinen, (oder sehr dickwandigen) Zellen gebildet. - Markfleckchen gegen aussen selten, gegen die Mitte häufig, gelbbraun. - Markstrahlen zahlreich, etwa 8 per $\mathrm{mm}$, schmal, fester als das umgebende Gewebe, etwas geschlängelt. - Poren an Grösse ziemlich abweichend, ziemlich zahlreich, etwa 30 Poren und Porengruppen per $\square \mathrm{mm}$, ziemlich fein, 1, 2, 3, auch mehr, und bis 8 in einer Gruppe, verzweigt gleichmässig zerstreut. - Gewebe fein, doch noch sichtbar schwammig. Ohne weitmaschigeres Gewebe. - Holzringe nur durch eine schmale braune Sommerholzlinie und eine häufig von der Grenze abgerückte Frühlingsporenlinie ziemlich deutlich, bauchigrund. - Holz gelblich oder röthlichweiss.

Populus alba $L$. Silberpappel. Mark 1 bis $2 \mathrm{~mm}$ dick, 5eckig, braun, aus sehr :feinen, ziemlich dickwandigen Zellen gebildet. Markfleckchen selten. - Markstrahlen sehr zahlreich, etwa 12 per mm, sehr fein, dichter als das frewebe, geschlängelt verlaufend. - Poren unbedeutend abweichend, sehr. zahlreich, etwa 50 Poren und Porengruppen per $\square \mathrm{mm}, 1$ bis 4, manchmal auch 5, 6, 7 bis zu 10, schwach mittler, gleichmässig oder baumartig gleichmässig. - Zellgewebe schwammig, ohne weitmaschigere 
Partieen. - Holzringe deutlich, durch eine dunklere Sommerlinie angezeigt, wenn auch gegen das Frühjahrsholz manchmal etwas verwaschen, weil ein Porenkreis bald vorhanden bald fehlend, rund oder etwas grobwellig rund. - Kern gelb oder braun, Splint weiss.

Populus nigra $L$. Schwarzpappel. Mark ungefähr $1 \mathrm{~mm}$ dick, 5eckigrund, grünlichweiss, in den Ecken grün, mit ungleich grossen, dünnwandigen, rundlicheckigen, feinen bis ziemlich feinen Zellen. Ohne Markfleckchen. - Markstrahlen sehr schmal, etwa 10 per mm. - Poren mittler, etwa 35 Poren und Porengruppen per $\square \mathrm{mm}, 1$ bis 6 , manchmal 7 , deutlich baumartig und gleichmässig zerstreut. Deutliches kleinerporiges Herbstholz. Frühlingskreis bald fehlend, bald vorhanden, daher Holzringe meist deutlich, öfters etwas winklich gerundet. Kern braun, Splint gelblichweiss. Sonst wie Silberpappel.

Populus tremula $L$. Aspe. Mark 0,5 bis $1 \mathrm{~mm}$ dick, grünlichweiss, fünfeckigrund, mit ungleichen, äusserst feinen bis sehr feinen eckigrunden Zellen. Markfleckchen gegen die Stammesmitte häufig, nach innen strablig. _ Markstrahlen wie bei Silberpappel. - Poren wenig abweichend, sehr zahlreich, etwa 40 Poren und Porengruppen per $\square \mathrm{mm}$, ziemlich fein, zu 1 bis 6 , auch 7 , gleichförmig, manchmal etwas baumartig zerstreut. — Gervebe wie bei Silberpappel. - Holzringe deutlich durch dunkleres und kleinerporiges Sommerholz und häufig eine Frühlingsporenlinie, schön gerundet, im höheren Alter etwas wellig. - Holz gelblichweiss oder weiss.

\section{Holzringe deutlich geschieden und am Anfange mit Linie oder Binde zahlreicherer oder gröberer Poren.}

a) Anfangsporen nicht gröber als sonst im Ring. Đ

Bemerkung. Je kräftiger das Wachsthum, je breiter dic Holzringe, desto weniger unterscheiden sich die Anfangsringporen von den übrigen, wogegen in engringig erwachsenem Stammholz und in Aesten gröberporige Anfangsringe häufig sind. Eine Regel den Prunusarten zu beachten ist.

1. Mit vielen breiten Markstrahlen.

Carpinus betulus $L$. Haine. Mark sehr klein, $1 \mathrm{~mm}$ dick, fünfeckig, bräunlich oder grünlich, aus dickwandigen, sehr feinen bis feinen Zellen gebildet. Sparsame Markfleckchen. Marlsstrahler senr zahlreich, etwa 10, auch mehr feine per mm, breit, doch zusammengesetzt, dichteren Gefüges, gerade verlaufend, die kleinen den Porengruppen ausweichend. In den Aesten ohne breite Markstrahlen. - Poren ziemlich abweichend, ziem- 
lich zahlreich, etwa 20 Poren und Porengruppen per $\square \mathrm{mm}$, ziemlich fein, 1, 2, 3 bis 16, bald breitstrahlig und verzweigt (in engjährigem Holz), bald bloss linienstrahlig. - Gewebe deutlich schwammig, mit linienfeinem, kreisig welligem weitmaschigeren Gewebe. - Holzringe deutlich durch dichtere dunkleres Herbstholz und etwas porenreichere, nicht gerade gröberporige Frühlingszone oder Frühlingslinie, sehr wellig, sich zwischen den grossen Markstrahlen gegen die Rinde ausbauchend. - Holz weiss.

Corylus avellana $L$. Hasel. Mark beiläufig 1 bis $3 \mathrm{~mm}$ dick, rund bis abgerundet dreieckig, röthlich, im Umfang aus. kleinen, dickwandigen, in der Mitte aus mittlern, eckigen, schwammigen Zellen gebildet. Wenige Markfleckchen. - Markstrahlen sehr zahlreich, etwa 12 per $\mathrm{mm}$, breit, zusammengesetzt, von dichterem Gefüge, leicht geschlängelt den Porengruppen ausweichend. - Poren wenig verschieden, ziemlich zahlreich, etwa 25 Poren und Porengruppen per $\square \mathrm{mm}$; selten zu wenigen, meist zu 5 bis 12 , schwach fein, linienartig gleichmässig oder breitstrahlig verzweigt. - Gewebe deutlich schwammig, mit linienfeinem, kreisigwelligem schwammigeren Gewebe. - Holzringe durch schmale dunkle Herbstlinie und in engjährigem Holze breiten, porenreichern, nicht gröberporigen innern Ring sehr deutlich, welch letzterer aber in breitringigen Holze ganz fehlt, wie bei Carpinus. - Holzringe fast kreisrund, nur leichtwellig. - Holz röthlichweiss oder weiss.

2. Mit ziemlich breiten Markstrahlen.

Ilex aquifolium $\boldsymbol{L}$. Stechpalme. Mark 0,5 bis $1 \mathrm{~mm}$ stark, rund oder eckigrund, grünlich, aus feinen, gegen aussen kleiner werdenden, ziemlich dickwandigen rundeckigen Zellen gebildet. Ohne Markfleckchen. - Markstrahlen sehr zahlreich, etwa 12 per mm, ziemlich breit, von etwas dichterem Gefüge, gerade. Poren zahlreich, etwa 20 Poren und Porengruppen per $\square \mathrm{mm}$, an Grösse merklich abweichend, grössere und kleinere zu Nestern und auch Linien vereinigt, äusserst fein, selten wenige, meist 5 bis 12 in einer Gruppe, schmalstrahlig verzweigt. - Gewebe sichtbar schwammig, in der Umgebung der Porengruppen und auch sonst unregelmässig weitmaschiger. - Holzringe kenntlich durch schmale dunklere Herbstlinie und porenreichere, nicht gröberporige Frühlingslinie, regelmässig kreisrund. - Holz grünlich.

Spartium scoparium L. Besenpfrieme. Ohne Markfleckchen. - Markstrahlen zahlreich, etwa 4 per mm, ziemlich breit, schwammiger als die Umgebung, ziemlich gerade verlaufend. Poren wenig verschieden, aber gegen das Ende des Jahresrings allmählich kleiner. werdend, zahlreich, 3 bis 4 Porengruppen per 
$\square \mathrm{mm}$, schwach fein, selten wenige, meist 5, 6, 7 bis 20 Poren in einer Gruppe, bald in porenreichen breiten kreisigen, bald in verzweigten Gruppen. - Gewebe sehr fein, mit kaum bemerkbaren kreisig welligen zahlreichen Linien schwammigeren Gewebes. - Holzringe deutlich durch etwas festeres Sommergewebe und porenreiches, nicht gröberporiges, Frühlingsband oder wenigstens hier engstehende verzweigtkreisige Porengruppen, schön kreisig gerundet. - Holz grünlich oder gelblichweiss.

3. Mit höchstens mittler breiten Markstrahlen.

c) Aussenporen verzweigt flammig gruppirt.

Rhamnus catharticus $\boldsymbol{L}$. Gemeiner Kreuzdorn. Mark $1 \mathrm{~mm}$ dick, rund, grünlichweiss, später röthlich, aus dünnwandigen, rundlichen, feinen Zellen zusammengesetzt. Ohne Markfleckchen. - Markstrahlen äusserst zahlreich, etwa 15 per mm, schmal, von dichterem Gefüge, gerade, kaum feingeschlängelt. - Poren wenig abweichend, nur gegen das Ende des Holzrings merklich abnehmend, sehr zahlreich, stets zu vielen, bis zu 50 in einer Gruppe, daher 100 bis 200 per $\square \mathrm{mm}$, sehr fein, verzweigtflammig. - Gewebe kaum und bloss stellenweise noch sichtbar. - Holzringe sehr ausgeprägt durch feine dunklere Sommerlinie und nicht gröberporiges Frühlingsporenband, schön rund. - Kern gelbroth, Splint weisslich- oder grünlichgelb.

$\beta)$ Aussenporen gleichmässig verzweigt gruppirt.

Populus monilifera Ait. G'emeine kanadische Pappel. Mark $1 \mathrm{~mm}$ dick, fünfeckig, grün, später röthlich, aus rundeckigen, dünnwandigen, sehr feinen Zellen gebildet. Einzelne Markfleckchen. - Markstrahlen sehr zahlreich, etwa 12 per mm, sehr schmal, von dichterem Gefüge, geschlängelt. - Poren sehr abweichend, gegen den Umfang der Ringe kleiner werdend, zahlreich, etwa 25 Poren und Porengruppen per $\square \mathrm{mm}$, ziemlich fein bis mittler, $\mathrm{zu} 1,2,3$, öfters auch 4 oder 5 in einer Gruppe, gleichmässig verzweigt, zerstreut. - Gewebe deutlich schwammig, ohne weitmaschigere Zellen. - Holzringe augenfällig durch kleinerporiges Sommerholz und häufig eine Linie oder ein Band porenreichern, aber nicht gerade gröberporigen Frühlingsholzes, schön, doch winklig gerundet. - Kern hell- oder graubraun. Splint gelblichweiss.

¡) Aussenporen leicht dendritisch oder peripherisch gleichmässig vertheilt.

Sambucus nigra L. Gemeiner Hollunder. Mark gross, bis $10 \mathrm{~mm}$ dick, rund, weiss, aus dünnwandigen, gröblichen oder ch stärkern Zellen gebildet. Ohne Markfleckchen. - Mark- 
strahlen sehr zahlreich, etwa 10 per mm, mittler breit, ungefähr dicht wie das Gewebe, gerade, doch etwas geschwungen. - Poren ziemlich abweichend, sehr zahlreich, etwa 50 Poren und Porengruppen per $\square \mathrm{mm}$, nesterweise, am Ende der Holzringe sehr plattgedrückt, 1, 2 bis 6 , auch öfters 7 in einer Gruppe, fein, zerstreut und leicht baumartig kreisig. - Gewebe etwas schwammig, mit einzelnen strahligen schwammigen Zellreihen. - Holzringe deutlich durch dunkleres Sommerholz und grossen Porenreichthum, aber nicht gröbere Poren des Frühlingsholzes; welligrund. - Holz gelblichweiss.

Sambucus racemosa $\boldsymbol{L}$. Traubenhollunder. Im Hólze wie der vorhergehende.

Prunus padus L. Traubenkirsche. Mark 2 bis $4 \mathrm{~mm}$ dick, eckigrund, weiss, aus dünnwandigen, feinen bis ziemlich feinen, rundeckigen Zellen gebildet. Ohne Markfleckchen. Markstrahlen sehr zahlreich, etwa 10 per mm, mittler breit, von dichterem Gefüge, gerade, nur die schmälsten den Poren etwas ausweichend. - Poren abweichend, besonders gegen den Umfang des Holzrings etwas kleiner werdend, zahlreich, etwa 60 Poren oder Porengruppen per $\square \mathrm{mm}, 1,2,3$ bis 6 , auch 7 in einer Gruppe, ziemlich fein, gleichmässig zerstreut, doch etwas baumartig und kreisig. Da und dort in den Ringen eine schmale porenarme Binde. - Holzgewebe noch sichtbar schwammig; einzelne Strahlenlinien und -felder etwas weitmaschiger. - Holzringe ziemlich deutlich, meist durch schmale dunklere Sommer- und anstossende einreihige, etwas gröberporige Frühlingslinie schön kreisrund. - Kern braurgelb. Splint gelblich weiss.

$\delta)$ Aussenporen etwas wurmförmig gleichmässig vertheilt.

Amelanchier vulgaris Moench. Mark sehr klein, 1/2 mm dick, rund, aus deutlich rundlichen, sehr feinen Zellen gebildet, weissroth. Ohne oder mit Markfleckchen. - Markstrahlen zahlreich, etwa 10 per mm, schmal, grobmaschiger als die Umgebung, gerade verlaufend. - Poren sehr verschieden an Grösse, sehr zahlreich, etwa 100 per $\square \mathrm{mm}$, von innen nach aussen in den Jahresringen kleiner werdend und hier sparsam, sehr fein, einzeln, gleichmässig zerstreut. - Gewebe noch sichtbar, wenn auch die Zellen sehr dickwandig. Ohne weitmaschigeres Gewebe. - Holzringe sehr deutlich, durch breite in die Augen springende Porenbinde, deren innerster Theil nicht gröberporig, schwach eckigrund. - Holz röthlichweiss. 
Amelanchier botryapium D.C. Wie der vorhergehende, nur Ringe breiter und eckiger.

Cydonia vulgaris Pers. Quitte. Mark $1 \mathrm{~mm}$ dick, zipfelig, rund, hellgrün, aus dickwandigen, eckigrunden, sehr feinen Zellen gebildet. - Markfleckchen sparsam, aber in der Nähe des Marks entschieden vorhanden. - Markstrahlen sehr zahlreich, etwa 12 per mm, schmal bis mittler, ziemlich gleich dicht mit der Umgebung, gerade verlaufend. - Poren gegen aussen im Ring an Grösse etwas abnehmend, nicht sehr zahlreich, doch etwa 100 per $\square \mathrm{mm}$, einzeln, sehr fein, etwas wurmförmig gleichmässig zerstreut. - Gewebe zur Noth sichtbar. - Holzringe deutlich durch den nicht sehr breiten, oft mit dem übrigen Ringe sich verschmelzenden unbedeutenden, im Anfange nicht gröberporigen Porenkreis, kaum etwas eckigrund. - Holz röthlichweiss.

Mespilus germanica L. Mispel. Mark 1 bis $2 \mathrm{~mm}$ dick, vieleckig rund, röthlich, aus ziemlich dickwandigen, rundlichen, gemischt verschieden grossen, feinen Zellen gebildet. Einige Markfleckchen. - Markstrahlen äusserst zahlreich, etwa 13 per mm, etwas stärker als schmal, dichter als das anstossende Gewebe, gerade, sich öfters auskeilend. - Poren wenig abweichend, zahlreich, etwa 100 per $\square \mathrm{mm}$, fein, einzeln, da und dort zu 2, selten 3, wurmförmig gleichmässig zerstreut. - Gewebe kaum sichtbar, mit zerstreuten und in radiale Linien gestellten weitmaschigern Zellen. - Holzringe sehr deutlich durch festeres kleinporiges Sommerholz, breite Binde zahlreicher nicht gröberer Poren, und an Markfleckchen erinnerndes, häufig ringsum laufendes Markgewebe auf der Grenze der Ringe, schön gerundet. Holz röthlich weiss.

Prunus avium L. Wildkirsche. Mark klein, $1 \mathrm{~mm}$ dick, eckigrund, grünlich, aus feinen bis ziemlich feinen, ziemlich dickwandigen, eckigrunden Zellen gebildet, bräunlich, im schmalen Umfange kleinerzellig. Ohne Markfleckchen. - Markstrahlen sehr zahlreich, etwa 10 per $\mathrm{mm}$, mittler bis ziemlich breit, dichtern Gefüges, gerade verlaufend, nur die feinsten etwas ausweichend. - Poren ziemlich verschieden, besonders gegen das Ende des Holzrings klein, zahlreich, etwa 30 Poren und Porengruppen per $\square \mathrm{mm}$, fein, 1, 2, 3 bis 8 in einer Gruppe, gleichmässig zerstreut, kaum etwas wurmförmig verzweigt. Auf porenreichen Frühlingsporenring folgt öfters eine porenarme Binde, die sich, in schwächerem Grad, auch noch weiter aussen wiederholen kann. Holzgewebe noch sichtbar :porös, mit einzelnen noch poröseren Feldern und strahligen Linien. - Holzringe recht deutlich durch dunkle, meist braune, schmale, klein- und porenarme Sommerlinie 
und sehr porenreiche, auch etwas gröberporige Frühlingsporenbinde oder wenigstens -linie, schön rund. - Kern gelbbraun. Splint röthlich weiss.

Prunus cerasus $L$. Weichselkirsche. Mark 0,5 bis $1 \mathrm{~mm}$ dick, eckigrund, rothbraun, mit nesterartig verbundenen zum Theil farberfüllten, eckigrunden, dünnwandigen, ziemlich feinen Zellen. Einzelne Markfleckchen gegen die Mitte. - Markstrahlen sehr zahlreich, etwa 8 per mm, stark mittler, kaum dichter als das anliegende Holzgewebe, gerade. - Poren ziemlich verschieden, besonders gegen den Umfang abnehmend, sehr zahlreich, etwa 70 Poren und Porengruppen per $\square \mathrm{mm}$, fein, zu 1, 2, 3 und bis zu 13 in einer Gruppe, zerstreut, dabei leicht wurmförmig verzweigt. - Gewebe, Holzringe und Holzfarbe wie bei avium.

Prunus domestica $L$. $Z_{\text {wets che. }}$ Mark sehr klein, $1 / 2 \mathrm{~mm}$ dick, eckigrund, bräunlich, aus sehr feinen bis feinen, eckigrunden, dünnwandigen Zellen gebildet, nur im Umfange massig, grünlich gefärbt. Ohne Markfleckchen. - Markstrahlen sehr zahlreich, etwa 8 per mm, mittler bis ziemlich breit, von dichterem Gefüge, gerade, nur die feinen geschlängelt ausweichend. Poren etwas abweichend, ziemlich zahlreich, etwa 40 Poren und Porengruppen per $\square \mathrm{mm}$, bei schmälern Jahresringen oft äusserst gedrängt stehend, im Kern vielfach mit gelber Masse erfüllt, zu 1, 2, 3, auch 4 in Gruppen und Nestern, fein, gleichmässig zerstreut, ganz leicht baumartig. - Holzgewebe kaum noch sichtbar schwammig, ohne weitmaschigeres Gewebe; höchstens da und dort etwas gröberporige Strahlenlinien. - Holzringe ziemlich deutlich (da und dort undeutlich), durch festeres, kleinerporigeres Sommerholz und gröberporige Frühlingsbinde oder -linie geschieden, grobwellig rund. - Kern blau- bis braunroth. Splint gelbweiss.

Prunus mahaleb L. Türkische Weichsel. Mark sehr klein, höchstens $1 \mathrm{~mm}$ dick, eckigrund, röthlich, aus dünnwandigen, sehr feinen, gegen den Umfang sich verkleinernden rundeckigen Zellen gebildet. Ohne Markfleckchen. - Markstrahlen sehr zahlreich, etwa 12 per mm, mittler bis ziemlich breit, dichtern Baues, unständig in der Dicke, da und dort sich auskeilend, die feinsten etwas ausweichend. - Poren abweichend, besonders gegen den Umfang der Ringe kleiner werdend, ziemlich zahlreich, etwa 40 Poren und Porengruppen per $\square \mathrm{mm}$, fein, 1, 2, 3 bis 8 , gleichmässig zerstreut, leicht verzweigt. - Gewebe kaum sichtbar schwammig, mit einzelnen weitmaschigeren Strahlenlinien und Feldern. - Holzringe ziemlich deutlich und wie bei Traubenkirsche wellig und bauchigrund.

Prunus spinosa L. Schwarzdorn. Mark 1 bis $2 \mathrm{~mm}$ dick, 
rund, weiss, später braun, aus dünnwandigen eckigen, ziemlich feinen Zellen gebildet. - Markfleckchen bald fast fehlend, bald zahlreich. - Markstrahlen sehr zahlreich, etwa 15 per mm, mittler bis ziemlich breit, etwas dichter als das Holzgewebe, sich vielfach auskeilend, geschwungen verlaufend, ohne den Poren auszuweichen. Diese ziemlich abweichend, gegen den Umfang der Ringe kleiner werdend, ziemlich zahlreich, etwa 70 Poren und Porengruppen per $\square \mathrm{mm}$, fein, zu 1, 2, 3, 4, manchmal 5, gleichmässig zerstreut, doch etwas wurm- oder baumartig. - Gewebe kaum mehr sichtbar, ohne weitmaschigere Partieen. - Holzringe deutlich durch Kleinerwerden der Poren gegen den Umfang, dunkle Sommerlinie und Frühlingsbinde oder -linie gröberer Poren, etwas welligrund. - Kern roth- bis schwarzbraun. Splint röthlich.

b) Anfangsporen gröber als die Aussenporen.

1. Poren gross und zahlreich, daher das Holz von siebartigem Ansehen.

Clematis vitalba $\boldsymbol{L}$. Waldrebe. Mark klein, $1 \mathrm{~mm}$ dick, eckigrund, schmutziggelb, aus feinen bis ziemlich feinen, innen dünn-, gegen aussen dickwandigen rundlicheckigen Zellen gebildet, unmittelbar in die ziemlich breiten bis breiten und daher ziemlich sparsamen ( 1 per $\mathrm{mm}$ ) Markstrahlen auslaufend, deren Gefüge dichter (?) als die Umgebung, im Verlaufe gerad. Ohue Markfleckchen. - Poren sehr verschieden; zwar sparsam (2-3 per $\square \mathrm{mm}$ ) und nur zu 1, manchmal 2, aber, weil grob, doch den grössern Theil der Fläche siebartig durchbrechend. In dem ziemlich scharf geschiedenen Herbstholze nur feine Poren. - Gewebe dicht, nicht mehr sichtbar. Ohne weitmaschigere Partieen. - Holzringe sehr augenfällig durch etwas porenarmes bis porenloses Sommerholz und Binde grobporigen Frühlingsholzes, winkligrund, an den Markstrahlen gegen aussen spitzig vorstehend. Gelbes Splintholz.

2. Poren breitstrahlig, schwanzförmig oder schwanzförmig und verzweigt.

Berberis vulgaris $\boldsymbol{L}$. Gemeiner Sauerdorn. Mark 3 bis $5 \mathrm{~mm}$ dick, leichteckigrund, gelb, aus dünnwandigen, etwas mittlern, eckigen Zellen gebildet. Sichtbar in die Markstrahlen verlaufend. Ohne Markfleckchen. - Markstrahlen ziemlich zahlreich, etwa 3 per mm, mittler breit, kaum lockerer als das Holzgewebe, fast ohne kleine Markstrahlen, gerade verlaufend. Poren sehr verschieden, ziemlich sparsam, etwa 60 Poren und Porengruppen per $\square \mathrm{mm}$, ziemlich fein bis mittler, einzeln, zu 2, manchmal auch 3 in einer Gruppe, schwanzförmig und verzweigt. 
- Gewebe nicht mehr erkennbar; weitmaschigeres Gewebe die Porengruppen hofähnlich umgebend. - Holzringe deutlich durch grobporigen Frühlingskreis und kleinporiges Sommerholz, beinahe kreisrund. - Kern bläulichroth. Splint schön gelb.

Castanea vesca Gärtn. Edelkastanie. Mark klein, $1 \mathrm{~mm}$ dick, deutlich, aber weniger stark fünfeckig als bei den Eichen, bräunlich, aus ziemlich dickwandigen, sehr feinen Zellen gebildet. Ohne Markfleckchen. - Markstrahlen sehr zahlreich, etwa 8 per mm, sehr schmal, von dichterem Gefüge, etwas geschlängelt, den Poren ausweichend. - Poren sehr verschieden, nicht sehr zahlreich, 1 bis 2 Gruppen per $\square \mathrm{mm}$, grob, einzeln, manchmal paarweise, häufig mit einem schwachen Hofe schwammigeren Gewebes, schwanzförmig und dabei häufig etwas verzweigt. - Gewebe deutlich schwammig mit etwas angedeutetem schmalen, kreisigwelligen schwammigeren Gewebe. - Holzringe sehr deutlich durch kleinporiges und feinkörniges Sommerholz und den weit gröberporigen Frühlingsporenkreis, etwas wellig rund, im Anfange sich dem fünfseitigen Mark anschliessend. - Kernholz hellbraun. Splint schmutzig gelblichweiss.

Quercus cerris $\boldsymbol{L}$. Zerreiche. Mark und Bau des Holzes wie bei Quercus pedunculata und robur, nur die grossen Markstrahlen, wenn auch nicht immer breiter, so doch zahlreicher.

Quercus pedunculata Willd. Stieleiche. - Mark 1 bis $4 \mathrm{~mm}$ dick, fünfeckigrund, weisslich, später bräunlich, aus feinen, runden, dickwandigen Zellen gebildet. Kleinere Markfleckchen sehe ich häufig im Innern von Schälwaldlohden. - Markstrahlen sehr zahlreich, etwa 12 per $\mathrm{mm}$, breit, etwas weniger dicht als die Umgebung, die stärkern gerade, sparsam, die sehr feinen den Poren ausweichend. - Poren äusserst verschieden: im Holzring von innen nach aussen bedeutend abnehmend, 1 bis 2 Gruppen per $\square \mathrm{mm}$, grob, einzeln, schwanzförmig verbunden. - Gewebe (noch eben sichtbar) etwas schwammig, mit äusserst zahlreichen kreisigwelligen Linien weiterer Zellen und Höfen solcher im Umfange der Porengruppen. - Holzringe sehr deutlich durch groben Frühlingsporenring, im Innersten des Stammes in stumpfeckiger Wellenlinie das fünfeckige Mark umziehend, zwischen den starken Markstrahlen etwas nach aussen gebaucht, daher auch im Ganzen etwas unregelmässig gerundet. - Kern röthlich-, gelblich-, schwärzlichbraun. Splint weiss.

Quercus robur $\boldsymbol{L}$. Traubeneiche, wie die vorhergehende.

3. Poren gleichmässig zerstreut, öfters etwas wurmförmig.

Amygdalus communis $L$. Mandelba um. - Mark $1 \mathrm{~mm}$ dick, weiss oder röthlich, rund bis fünfeckig, aus ziemlich dïnnwandigen, 
rundlicheckigen, feinen Zellen gebildet. Ohne Markfleckchen. Markstrahlen sehr zahlreich, etwa 12 per mm, mittlerbreit, gröberzellig? als das umliegende Gewebe, fast gerade verlaufend, beim Durchgang durch die Frühlingsporenkreise anschwellend. — Poren sehr verschieden an Grösse, sparsam, etwa 40 Poren und Porengruppen per $\square \mathrm{mm}$, ziemlich fein bis mittler, zu 1,2,3 bis ein Dutzend, gleichmässig zerstreut, etwas verzweigt. - Gewebe kaum mehr sichtbar. Weitmaschigeres in sehr feinen, fast nicht kenntlichen Kreislinien. - Holzringe durch starken Frühlingskreis und kleinporiges Sommerholz sehr deutlich, ziemlich schön gerundet. Kern braun. Splint röthlichweiss.

Ligustrum vulgare $L$. Rainweide. Mark 1 bis $2 \mathrm{~mm}$ dick, rund, weiss, aus gleichförmigen, feinen, dünnwandigen, eckigen Zellen bestehend, im Umfang eine schmale, aus feinkörnigen braunen Zellen gebildete Binde. Ohne Markfleckchen. - Markstrahlen sehr zahlreich, etwa 15 per mm, sehr schmal, von dichterem Gewebe, etwas geschlängelt. - Poren ungleich, in den Ringen von innen nach aussen bedeutend abnehmend, sehr zahlreich, d. h. etwa 100 per $\square \mathrm{mm}$, fein, zu 1, 2, auch 3, selten 4, gleichmässig zerstreut bis etwas wurmförmig verzweigt. Gewebe kaum sichtbar schwammig, einzelne strahlige Linien weitmaschiger. - Holzringe deutlich durch das kleinporige Sommerholz, eine dunkle Grenzlinie und eine deutliche gröberporige Frühlingslinie oder -binde, welche sich auch öfters mehrfach und nicht immer parallel im weitern Holzringe wiederholt, welligrund. Kern violetbraun. Splint weiss.

Lonicera tatarica $L$. Tatarische Heckenkirsche. Mark 1 bis $3 \mathrm{~mm}$ dick, eckigrund, braun, in der Mitte hohl, aus dünnwandigen rundeckigen feinen, gegen aussen kleineren Zellen gebildet. Ohne Markfleckchen. - Markstrahlen sehr zahlreich, etwa 15 per mm; mittler, schmal, von verschiedener Stärke, von schwanmigerem Gefüge, zumal an den kleinen Markstrahlen sichtbar, gerade, sich vielfach auskeilend. - Poren sehr abweichend, gegen aussen im Ring allmählich verschwindend, zahlrejch, etwa 80 Poren und Porengruppen per $\square \mathrm{mm}$, fein, zu 1, 2, selten 3 bis 5, leichtverzweigt, gleichmässig zerstreut. Gewebe nicht mehr sichtbar. Weitmaschigeres Gewebe fehlend. - Holzringe sehr deutlich durch starke Frühlingsporenbinde und Verschwinden der Poren am Umfange der Ringe, kaum etwas eckigwellig kreisrund. - Kern bräunlichgelb.

Lonicera xylosteum L. Gemeine Heckenkirsche. Mark nur $1 \mathrm{~mm}$ dick. Sonst wie tatarica. Aber Poren am Anfange kaum gröber als sonst im Ring, auch häufig keine Binde, sondern nur eine Linie bildend. 
Syringa vulgaris $\boldsymbol{L}$. Gemeine Syring e, gemeiner Flieder. - Mark 1 bis $2 \mathrm{~mm}$ dick, 4-, auch 5-oder 6eckigrund, weiss, aus dünnwandigen ziemlich feinen Zellen gebildet. Ohne Markfleckchen. - Markstrahlen sehr zahlreich, etwa 15 per $\mathrm{mm}, 0,4 \mathrm{~mm}$ hoch, schmal, dichter (?) als das umliegende Gewebe, etwas geschwungen verlaufend und den Poren leicht ausweichend. - Poren merklich abweichend, besonders gegen den Umfang der Ringe kleiner werdend, da und dort schichtweise gehäuft, sonst ziemlich sparsam, etwa 60 Poren und Porengruppen per $\square \mathrm{mm}$, schwach fein oder fein, einzeln, 2, 3, manchmal 4 oder 5, gleichmässig, etwas baumartig vertheilt. Gewebe kaum noch sichtbar schwammig. Etwas weitmaschigeres Gewebe daj und dort Porengruppen, auch die sekundären Porenschichten umgebend, und in sehr feinen umfänglichen Linien (?). - Holzringe sehr deutlich durch ein Band oder wenigstens eine Linie gröberer Frühlingsporen und sparsam- und kleinerporiges Sommerholz, etwas unregelmässig geschwungen.Kern violetbraun oder bläulichroth.

4. Poren verzweigt, kreisig, oder beides, häufig zerstreut beginnend.

«) Mit ausgeprägt baumartig kreisiger Vertheilung der Aussenporengruppen.

Celtis australis $L$. Zürgelbaum. Mark 1, höchstens $2 \mathrm{~mm}$ dick, länglich oder rundeckig, grünlich, mit dickwandigen eckigrunden feinen am Umfange kleinern Zellen. - Ohne Markfleckchen. Markstrahlen ziemlich sparsam, etwa 3 per mm, mittler bis ziemlich breit, kaum dichter als das sonstige Holzgewebe, geschwungen gerade, beim Uebergang in den kleinerporigen Aussenring öfters geknickt, wie am Anfang der Holzringe, den Poren leicht ausweichend. - Poren sehr verschieden, im grösseren Innenring nur etwa 1 Dutzend schwach grobe, im Aussenring wohl doppelt so viel bis sehr feine Poren und Porengruppen. - Die Poren zu mehreren bis 6 in nestförmigen, da und dort auch radialen oder schwanzförmigen Gruppen stehend. Diese von der weitporigen Innenzone nach aussen mehr und mehr dendritisch, am Umfang öfters dabei schön kreisig gestellt. - Gewebe sichtbar etwas schwammig mit weitmaschigeren radialen Linien und solchen Höfen um die zumal äusseren Porengruppen. - Jahresringe sehr deutlich durch dichten kleinporigen Umfang und starkporigen Frühlingskreis, gut gerundet. - Kern grünlichgrau oder -braun. Splint blassgelb. (Der Beschreibung in Bd. III. der Querschnitte von 100 Holzarten offenbar Schnitte der nachfolgenden $\mathrm{zu}$ Grunde gelegen.)

Celtis occidentalis $\boldsymbol{L}$. Von dem vorhergehenden (ob immer?) verschieden durch zahlreichere Markstrahlen (etwa 6 per $\mathrm{mm}$ ), 
porenreichere, nur ziemlich grobe Poren führende Frühlingsbinde und gleichmässigere Vertheilung schwächerer Poren im Aussenring.

Cytisus alpinus $L$. und laburnum $L$. Alpenbohnenbaum und gemeiner Bohnenbaum, Goldregen. - Mark klein, $1 \mathrm{~mm}$ dick, eckigrund, gelblich, aus eckigen, dünnwandigen, ziemlich feinen bis mittlern Zellen gebildet. Ohne Markfleckchen. - Markstrahlen sehr zahlreich, etwa 4 per $\mathrm{mm}$, ziemlich breit, schwammiger (?) als das Holzgewebe, von geradem Verlauf. - Poren sehr verschieden, allmählich in den Ringen von innen nach aussen abnehmend, ziemlich sparsam, etwa 8 Gruppen per $\square \mathrm{mm}$, mittler, zu 1, 2, 3 bis mehreren Dutzenden, verzweigt, auch kreisig gruppirt. - Gewebe fein, nicht mehr sichtbar. Die Porengruppen von weitmaschigerem Gewebe hofähnlich umgeben. - Holzringe sehr deutlich durch allmähliches Kleinerwerden der Porengruppen am Umfang und die starke Porenbinde am Anfang; schön gerundet. - Kernholz gelbbraun, Splint gelb.

Hedera helix $L$. Epheu. Mark $1 \mathrm{~mm}$ dick, rund. Ohne Markfleckchen. - Markstrahlen sehr zahlreich, etwa 6 per mm, ziemlich breit bis breit, von schwammigerem Gefüge als das Holzgewebe und geradem Verlauf. - Poren verschieden, von innen nach aussen in den Ringen kleiner werdend, sehr zahlreich, etwa 20 Gruppen per $\square \mathrm{mm}$, ziemlich fein, zu 1 bis 5, manchmal 6, verzweigtkreisig. - Gewebe noch etwas sichtbar schwammig. Etwas weitmaschigeres Gewebe in der Umgebung der Porengruppen. - Holzringe deutlich durch einen porenlosen Streifen festern Sommerholzes und eine gröberporige Linie oder Binde am Anfange, ziemlich schön gerundet, meist etwas exzentrisch. - Holz gelblichweiss.

Robinia pseudoacacia! L. Gemeine Robinie, falsche Akazie. Mark 2 bis $3 \mathrm{~mm}$ dick, fünfeckig rund, jung weiss mit grünem Umfang, aus sehr dünnwandigen, gröblichen, nur im schmalen Umkreis feinkörnigern Zellen gebildet, älter rothbraun. Ohne Markfleckchen. - Markstrahlen zahlreich, etwa 5 per mm, mittler breit, kaum dichtern Gefüges als die Umgebung, den Poren stark ausweichend. - Poren von innen nach aussen in den Ringen sehr abweichend, ziemlich zahlreich, doch nur 4 bis 5 Gruppen per $\square \mathrm{mm}$, einzeln, manchmal paarweise, in den Gruppen nach aussen bis 10, grob, zerstreut bis verzweigt und kreisig. - Gewebe noch sichtbar porös; weitmaschigeres Gewebe in einzelnen radialen Linien oder Feldern, zumal im Frühlingsring, und hofähnlich in der Umgebung der äussern Porengruppen. - Holzringe sehr deutlich, wegen festern Sommer- und lockeren Frühlingsholzes und starker gröberporiger Binde, innen ziemlich schön rund, gegen 
den Umfang des Baumes den Rinderissen entsprechend, winkligrund. - Kern grünlichgelb oder gelbbraun. Splint weissgelb.

Ulmus campestris $\boldsymbol{L}$. Ge meine Ulme. - Mark 1 bis $2 \mathrm{~mm}$ stark, eckigrund, weiss, aus dünnwandigen, eckigen, mittlern Zellen gebildet; nur im Umfang ein dunkler, dichter Kreis. Ohne Markfleckchen. - Markstrahlen sehr zahlreich, etwa 6 per mm, fein bis mittler breit, von dichterem Gewebe, die feinern geschlängelt. - Poren sehr verschieden, in den Holzringen von innen nach aussen stetig abnehmend, zahlreich, d. h. 4 bis 6 Gruppen per $\square \mathrm{mm}$, zu 1, 2, 3 bis mehreren Dutzenden, gröblich, verzweigt kreisig. - Gewebe sichtbar feinschwammig, öfters in beschränkter Umgebung der Porengruppen etwas weitmaschiger, und solches auffallender Weise auch in einzelnen durch je zwei stärkere Markstrahlen gebildeten, strahligen Feldern. - Holzringe sehr deutlich durch festeres, kleinporiges Sommerholz, neben der augenfälligen gröberporigen Linie am Anfang und dem Porenreichthum des Frühlingsringes überhaupt, etwas stumpfwinklig rund. - Kern braunroth oder braun bis fleischroth. Splint weiss oder gelb.

Ulmus effusa Willd. Flatterulme. Aehnlich der Ulmus campestris. Der häufige viel reichere Frühlingsporenkreis wahrscheinlich Folge üppigern Wachsthums; doch fallen ausserdem noch schön verbundene Aussenporengruppen und Mangel der schwammigen Felder auf.

$\beta$ ) Mit Andeutung dendritisch peripherischer Vertheilung der Aussenporen oder Aussenporengruppen.

* Poren grob oder ziemlich grob.

Ailanthus glandulosa Desf. G ötte r b a u m. Mark gross, 4 bis $8 \mathrm{~mm}$ dick, dreieckig bis rund, weiss oder röthlich, aus ziemlich dünnwandigen eckigrunden, ziemlich feinen bis mittleren Zellen gebildet. Ohne Markfleckchen. - Markstrahlen ziemlich zahlreich, doch nur etwa 3 per mm, ziemlich breit, dichter als das übrige Gewebe, gerade, obschon den stärksten Poren etwas ausweichend. - Poren zum Umfange der Ringe bedeutend kleiner werdend, ziemlich sparsam, etwa 2 Poren und Porengruppen per $\square \mathrm{mm}$, grob, zu 1, 2,3, manchmal 4 oder 5 , in den kleinporigen Gruppen bis 9, zerstreut, verzweigtkreisig. - Gewebe sichtbar locker. Nur Spuren weitmaschigeren Gewebes in der Umgebung der Porengruppen, aber einzelne radiale Zellenreihen und einzelne Felder zwischen je 2 Markstrahlen besonders schwammig. - Holzringe sehr augenfällig durch das porenarme Sommerholz und den gröberporigen Frühlingskreis, schön rund. - Kern grauorange. Splint gelbweiss. 
Bignonia catalpa $L$. Trompetenbaum. - Mark ziemlich gross, 3 bis $5 \mathrm{~mm}$ dick, rund, mit stumpfen Ausbauchungen, gelblich, aus mittlern, dünnwandigen, eckigen Zellen zusammengesetzt. Ohne Markfleckchen. - Markstrahlen zahlreich, etwa 7 per $\mathrm{mm}$, schmal, von dichterem Bau, geschlängelt den Poren ausweichend und sich vielfach auskeilend. - Poren ziemlich verschieden, mittler zahlreich, etwa 8 Poren und Porengruppen per $\square \mathrm{mm}$, ziemlich grob, in den Ringen von innen nach aussen an Grösse abnehmend, zu 1, 2, 3 , manchmal 4 oder 5 in einer Gruppe, zerstreut, etwas baumartig.Gewebe noch sichtbar schwammig mit einzelnen weitmaschigen strahligen Linien und Höfen um die Aussengruppen. - Holzringe durch porenarme und kleinporige Sommerlinie und weitporige Frühlingsbinde oder -linie sichtbar, grobwellig rund. - Kern graubraun. Splint schmutzigweiss.

Fraxinus excelsior $\boldsymbol{L}$. Gemeine Esche. Mark beiläufig $4 \mathrm{~mm}$ dick, fünfeckigrund, weiss, am Saume bräunlich, aus ziemlich feinen, dünnwandigen, eckigrunden Zellen gebildet. Ohne Markfleckchen. - Markstrahlen sehr zahlreich, etwa 5 per mm, schmal, kaum dichter als das umliegende Gewebe, gerade, aber den Porengruppen sorgfältig ausweichend. - Poren auf der grössern Fläche der Holzringe sparsam, etwa 4 Poren und Porengruppen per $\square \mathrm{mm}$, an Grösse vom Frühling zum Herbst bis zum Verschwinden abnehmend, zu 1, 2, auch 3 und 4 gruppirt, ziemlich grob, zerstreut und verzweigt, auch kreisig. - Gewebe deutlich locker. Hofähnliche weitmaschigere Umgebung der äussern Porengruppen auch häufig etwas schwammigere Felder zwischen je 2 Markstrahlen. - Holzringe äusserst deutlich durch die porenlose Sommerlinie und den starken gröberporigen Frühlingsstreifen, kreisrund, in ältern Stämmen nach den Rinderissen eckigrund. Kern braun. Splint weiss.

Gleditschia triacanthos $\boldsymbol{L}$. Gemeine Gleditschie. Mark $2 \mathrm{~mm}$ dick, stumpfeckigrund, grünlich, später röthlich, aus dünnwandigen, eckigen, feinen, gegen aussen kleiner werdenden Zellen gebildet. Ohne Markfleckchen. - Markstrahlen zahlreich, etwa 7 per $\mathrm{mm}$, ziemlich breit, von kaum dichterem Gewebe als die Umgebung, den Poren etwas ausweichend, gerade. Poren sehr verschieden, aussen in den Ringen sparsam, etwa 6 Poren und Porengruppen per $\square \mathrm{mm}$, von innen nach aussen bis zum Verschwinden abnehmend, ziemlich grob bis grob, einzeln, paarweise, manchmal zu 3 oder 4 , zerstreut bis leichtverzweigtkreisig. - Holzgewebe kaum sichtbar porös, zwischen den Frühlingsporen aber und in der Umgebung der Aussenporen hofähnlich weitmaschig. - Holzringe äusserst deutlich durch kleinporiges festeres Sommerholz und breite weitporige Frühlingsbinde, schön rund. - Kern roth. Splint röthlich-grünlich-gelblich. 
Hippophaë rhamnoides $\boldsymbol{L}$. Seekreuzdorn. Mark 3 bis $4 \mathrm{~mm}$ dick, eckigrund, bräunlich, aus dünnwandigen, eckigrunden, nur in einer schmalen, dunklen Linie feinkörnigen Zellen. Ohne Markfleckchen. - Markstrahlen sehr zahlreich, etwa 12 per mm, schmal, von dichterem Gefüge, stark geschlängelt, sich zwischen den Poren durchwindend. - Poren sehr ungleich, von innen nach aussen in den Ringen äusserst abnehmend, sehr zahlreich, etwa 50 Poren und Porengruppen per $\square \mathrm{mm}$, ziemlich grob, meist oval, einzeln, paarweise, manchmal zu 3, selten 4 in einer Gruppe; zwischen den Gruppen starker Poren einzelne zerstreute kleine Poren; Frühlingskreis mit kleinen Poren beginnend; zerstreut. - Holzgewebe noch sichtbar etwas schwammig, besonders in der Frühlingsporenbinde, in einzelnen radialen Linien und zuweilen auch am Ende der Holzringe. Diese sehr deutlich, durch eine Binde kleinporigen Sommerholzes und eine öfters ebenso breite oder breitere starke Frühlingsporenbinde. - Kern gelbbraun. Splint gelblich.

Morus alba $\boldsymbol{L}$. und M. nigra $\boldsymbol{L}$. Weisser und schwarzer Maulbeerbaum. Mark 2 bis $5 \mathrm{~mm}$ dick, rund oder länglich, weiss, aus eckigrunden, mittlern, dünnwandigen, nur im Umfang dickwandigern Zellen zusammengesetzt. Ohne Markfleckchen. Markstrahlen sehr zahlreich, etwa 5 per mm, mittler bis ziemlich breit, von dichterem Bau als das Holzgewebe, gerade verlaufend, nur die feinen ausweichend. - Poren sehr verschieden, von innen nach aussen in den Ringen abnehmend, ziemlich zahlreich, etwa 12 Poren und Porengruppen per $\square \mathrm{mm}$, ziemlich grob bis grob, einzeln, paarweise, manchmal zu 3, in den kleinen Gruppen bis zu 8 , zerstreut und verzweigt, manchmal kreisig. - Gewebe kaum sichtbar schwammig; etwas weitmaschigeres Gewebe in der Umgebung der Porengruppen und da und dort in Form von schmalen welligkreisigen Linien. - Holzringe sehr deutlich durch porenarmes Sommerholz und grobporige Frühlingsbinde, ziemlich schön gerundet. - Kern gelbbraun. Splint gelbweiss.

Paulownia imperialis Sieb. Pa u lownie. Mark stark, bis $10 \mathrm{~mm}$ dick, ziemlich rund, weiss, sehr schwammig, aus dünnwandigen, mittlern Zellen gebildet, später hohl. Ohne Markfleckchen. - Markstrahlen sehr zahlreich, etwa 5 per mm, mittler bis ziemlich breit, von dichterem Gefüge, sich oft auskeilend, von geradem Verlauf. Poren ziemlich verschieden, von innen nach aussen in der Regel allmählig abnehmend, ziemlich sparsam, etwa 35 Poren und Porengruppen per $\square \mathrm{mm}$, ziemlich grob, einzeln, paarweise, manchmal zu 3, zerstreut, verzweigt kreisig. - Gewebe deutlich schwammig, mit noch schwammigerem Gewebe in der Umgebung und zu Ver- 
bindung der Porengruppen unter sich. - Holzringe deutlich durch porenarmes Sommerholz und eine lockere Binde gröberporigen Frühlingsholzes, schön gerundet. - Holz röthlichweiss.

** Poren mittler bis ziemlich fein.

Rhamnus frangula L. Pulverholz. Mark $1 \mathrm{~mm}$ dick, rund, röthlich, aus feinen, ziemlich dünnwandigen, eckigen Zellen gebildet, nur im schmalen Umfange feinkörniger. Ohne Markfleckchen. - Markstrahlen zahlreich, etwa 8 per mm, schmal, dichter als die Umgebung, gerade, den Poren etwas ausweichend. Poren im Holzring von innen nach aussen stetig und sehr bedeutend abnehmend, ziemlich sparsam, etwa 16 Poren und Porengruppen per $\square \mathrm{mm}$, ziemlich fein, zu $1,2,3$ bis 6 , auch 7 , zerstreut bis baumartig. - Gewebe sichtbar schwammig, da und dort felderweise etwas weitmaschiger. - Holzringe deutlich durch dichteres kleinporiges Sommerholz und starke gröberporige Frühlingsbinde, eckigrund. - Kern gelbroth. 'Splint hellgelb.

Rhus cotinus $L$. Perrückenstrauch. Mark 1 bis $2 \mathrm{~mm}$ dick, rund, gelblich oder röthlich, aus dünnwandigen ziemlich feinen, gegen aussen kleiner werdenden, nesterartig gruppirten, mit zerstreuten dickwandigen dunklern durchschossenen Zellen gebildet. Ohne Markfleckchen. - Markstrahlen sehr zahlreich, etwa 10 per mm, schmal, dichter als das Holzgewebe, den Poren ausweichend. - Poren sehr abweichend, im äussern Ringtheile sparsam, etwa 14 Poren und Porengruppen per $\square \mathrm{mm}$, mittler, zu 1 bis 6 , auch 7 in einer Gruppe, zerstreut bis verzweigt und kreisig. - Gewebe kaum noch sichtbar schwammig, mit etwas weitmaschigerem Gewebe um die Porengruppen und in Form strahliger Linien. - Holzringe sehr deutlich durch den breiten Frühlingsporenkreis und Porenarmuth und -kleinheit im äussern Theil der Ringe, regelmässig, aber etwas welligrund. - Kern goldgelb. Splint weiss.

Rhus typhina L. Essigbaum. Im Bau wie Perrückenstrauch, aber Mark bis $5 \mathrm{~mm}$ dick, gelblich oder bräunlich, aus nesterartigen ziemlich feinen bis mittlern Zellen zusammengesetzt. - Holzringe regelmässiger kreisförmig. - Kern graugrünlich. Splint schmutzig gelbweiss.

Tamarix gallica $\boldsymbol{L}$. Französische Tamariske. Mark 1 bis $2 \mathrm{~mm}$ dick, abgerundet eckig, bräunlich, aus eckigrunden, etwas unregelmässigen, ziemlich feinen, dünnwandigen, im Umkreise des Marks kleiner werdenden Zellen gebildet. Ohne Markfleckchen. - Markstrahlen zahlreich, etwa 4 oder 5 per mm, ziemlich breit, im Gefüge ungefähr wie die Umgebung, ziemlich gerade verlau- 
fend. - Poren von innen gegen aussen im Ring ziemlich allmählich und fast bis zum Verschwinden abnehmend, ziemlich zahlreich, etwa 10 Poren und Porengruppen per $\square \mathrm{mm}$, zu 1, 2, 3, manchmal 4 oder 5, mittler, gleichmässig bis leicht kreisig. - Gewebe noch sichtbar schwammig, die Porengruppen häufig mit einem Hof weitmaschigeren Gewebes, besonders im Ringanfang. Holzringe sehr deutlich durch festeres kleinerporiges Herbstholz und breite gröberporige Frühlingsbinde oder sich mehrfach im Holzring wiederholende Frühlingslinie, etwas bauchig rund. Kern braunroth. Splint grünlich-gelblich-weiss.

Tamarix germanica $\boldsymbol{L}$. Deutsche Tamariske. Mark linsengross, rund. Ohne Markfleckchen. - Markstrahlen sehr zahlreich, etwa 8 per mm, mittler bis ziemlich breit, in der Breite unbeständig, etwas lockerer als die Umgebung, ziemlich gerade verlaufend. - Poren vom Frühlingsring $a b$ an Grösse stark abnehmend, da und dort noch eine sekundäre Kreislinie bildend, aussen im Ringe verschwindend klein, sparsam, etwa 16 Poren und Porengruppen per $\square \mathrm{mm}$, ziemlich fein, 1, 2 auch 3 in einer Gruppe, gleichmässig zerstreut, auch etwas kreisig und verzweigt, noch sichtbar schwammig. Etwas weitmaschigeres Gewebe in der Umgebung der Porengruppen, besonders am Ringsanfang und -ende. - Holzringe deutlich durch porenärmeres und kleinerporiges Herbstholz und die schmale gröberporige Frühlingsbinde, etwas bauchig gerundet. - Holzfarbe grünlich oder gelblichweiss. 


\section{Inhaltsverzeichniss.}

A.

Abies excelsa 6 .

" pectinata 5.

Acer campestre 9.

" negundo 9.

" platanoides 9 .

" pseudoplatanus 10.

" dasycarpum 10.

Aesculus hippocastanum 13.

A horn, gemeiner 10.

"Silber- 10.

"Spitz- 9.

$" \quad$ eschenblättriger 9 .

Ailanthus glandulosa 30 .

Akazie, falsche 29.

Alnus glutinosa 12.

" incana $1 \%$.

$"$ viridis 12 .

Alpenbohnenbaum 28.

Amelanchier botryapium 23. vulgaris 22.

Amygdalus communis 26.

Apfelbaum 15.

Arve 8.

Aspe 19.

B.

Berberis vulgaris 25 .

Bergdrossel 12.

Besenpfrieme 20.

Betula alba 18.

Bignonia catalpa 31 .

Birke, gem. 18.
Birnbaum 15.

Bohnenbaum, Alpen- 28.

$"$

gemeiner 28.

Buche, gem. 12.

Buchs 10.

Buxus sempervirens 10.

C.

Carpinus betulus 19.

Castanea vesca 26.

Celtis australis 28.

" occidentalis 28 .

Clematis vitalba 25.

Cornus mascula 13.

" sanguinea 14.

Corylus avellana 20.

Crataegus oxyacantha 14.

Cydonia vulgaris 23.

Cytisus alpinus 29.

" laburnum 29.

E.

Edelkastanie 26.

Eibe 6.

Eiche, Stiel- 26.

"Trauben- 26.

"Zerr- 26.

Elsebeer 16.

Epheu 28.

Erle, gemeine 12.

" Grau- 17.

Esche, gem. 30.

Essigbaum 33.

Evonymus europaeus 14. 
F.

Fagus sylvatica 12.

Fichte 6.

Flatterulme 30.

Flieder, gem. 27.

Föhre, gemeine 7.

$"$ Schwarz- 7.

"Leg- 6.

Weymouths- 8 .

Fraxinus excelsior 31.

\section{G.}

Gleditschia triacanthos 31 .

Gleditschie, gem. 31.

Götterbanm 30.

Granerle $1 \%$.

H.

Haine 19.

Hartriegel 14.

Hasel 20.

Heckenkirsche, tatarische 27.

Hedera helix 29.

gemeine 27.

Hippophaë rhamnoides 32 .

Hollunder, gem. 21.

» Trauben 22.

I。

Ilex aquifolium 20.

J.

Johannisbeere, schwarze 11.

Juglans regia 11.

n nigra 11.

Juniperus communis 5 . ” virginiana 6 .

K.

Kirsche, Trauben- 22.

$" \quad$ Wild- 23.

"Weichsel- 24.

Knackweide 18.

Kornelkirsche 13.

Kreuzdorn, gem. 21.
L.

Lärche, gem. 7.

Larix europaea 7.

Lebensbaum, gemeiner 6 .

Legföhre 6 .

Ligustrum vulgare $2 \%$.

Linde, grossblättrige 13.

" kleinblättrige 13.

Liriodendron tulipifera 15.

Lonicera tatarica 27.

" xylosteum 27.

Lorbeerweide 18.

II.

Mandelbaum 26.

Mandelweide 18.

Massholder 9.

Maulbeerbaum, weisser 32.

Mehlbaum 15. schwarzer 32 .

Mespilus germanica 23 .

Mispel 23.

Morus alba 32.

$» \quad$ nigra 32 .

\section{N.}

Nussbaum, gem. 11.

$" \quad$ Schwarz 11.

P.

Pappel, Schwarz- 19.

"Silber- 18.

" gem. kanad. 21.

Paulownia imperialis 32 .

Paulownie 32.

Perrückenstrauch 33.

Pfaffenhütchen 14.

Pfeifenstrauch, gem. 11.

Philadelphus coronarius 11.

Pimpernuss 16.

Pinus montana 7.

$"$ cembra 8 .

n strobus 8.

$"$ sylvestris 7 .

" laricio v. austriaca 7.

$" \quad "$ corsicana 7 . 
Pirus aria 15.

" communis 15.

” malus 15.

- " torminalis 16 .

Platane, gem. 12.

Platanus vulgaris 12.

Populus alba 18.

$" \quad$ monilifera 21.

" nigra 19.

„ tremula 19.

Prunus avium 23.

$"$ cerasus 24.

" domestica 24.

" mahaleb 24 .

" spinosa 24.

" padus 22.

Pulverholz 32.

\section{Q.}

Quercus cerris 26.

" pedunculata 26.

n robur 26.

Quitte 23.

R.

Rainweide $2 \%$.

Rhamnus catharticus 21.

frangula 33.

Rhus cotinus 33 .

" typhina 33.

Ribes nigrum 11.

Robinia pseudoacacia 29.

Robinie, gem. 29.

Rosskastanie 13.

\section{s.}

Salix alba 17.

" amygdalina 18.

" caprea 18.

" daphnoides 18.

" fragilis 18.

" triandra 18.

Salweide 18.

Sambucus nigra 21. $" \quad$ racemosa 22.

Sauerdorn, gem. 25.

Seekreuzdorn 31.
Schlingstrauch 16.

Schneeball, gem. 17.

Schwarzdorn 24.

Schwarzföhre 7.

Schwarznussbanm 11.

Schwarzpappel 19.

Silberahorn 10.

Silberpappel 18.

Sorbus aucuparia 16.

, domestica 16.

Spartium scoparium 20.

Sperberbaum 16.

Spitzahorn 9.

Staphylea pinnata 16 .

Stechpalme 20.

Stieleiche 26.

Syringa vulgaris 28.

Syringe, gem. 27.

T.

Tamariske, deutsche 34 .

" französische 33.

Tamarix gallica 33 .

" germanica 34 .

Tanne 5.

Taxus baccata 6 .

Thuja occidentalis 6 .

orientalis 6 .

Tilia grandifolia 13 .

" parvifolia 13.

Traubeneiche 26 .

Traubenhollunder 22 .

Traubenkirsche 22 .

Trompetenbaum 30 .

Tulpenbaum 15.

U.

Ulme, gem. 30 .

" Flatter- 30.

UImus campestris 29.

" effusa 30 .

\section{V.}

Viburnum lantana 16. opulus 17.

Vitis vinifera 8 .

Vogelbeer 16. 
w.

Wachholder, gemeiner 5 . » virginischer 6 .

Waldrebe 25 .

Wasserholder $1 \%$.

Weichselkirsche 24 .

Weichsel, tiirk. 24.

Weide, Weiss- 17.

, Sal- 18.

" Lorbeer- 18.

"Knack- 18.

" Mandel- 18.
Weinrebe 8.

Weissdorn, gem. 14.

Weissweide 17.

Wellingtonia gigantea 6 .

Weymouthsföhre 8 .

Wildkirsche 23 .

Z.

Zerreiche 26.

Zürgelbanm 28.

Zwetsche 24 . 

